NBER WORKING PAPER SERIES

\title{
WHO BENEFITS WHEN THE GOVERNMENT PAYS MORE? PASS-THROUGH IN THE MEDICARE ADVANTAGE PROGRAM
}

\author{
Mark Duggan \\ Amanda Starc \\ Boris Vabson \\ Working Paper 19989 \\ http://www.nber.org/papers/w19989 \\ NATIONAL BUREAU OF ECONOMIC RESEARCH \\ 1050 Massachusetts Avenue \\ Cambridge, MA 02138 \\ March 2014
}

We thank Josh Gottlieb, Jon Kostad, Kurt Lavetti, David Molitor, Neale Mahoney, Ashley Swanson, Bob Town, and seminar participants at Stanford, UCSB, and the ASSA meetings for helpful comments. The views expressed in this paper are solely those of the authors and do not necessarily represent the views of the institutions or other individuals mentioned above, nor of the National Bureau of Economic Research. All errors are our own. Boris Vabson acknowledges funding from the NBER Pre-Doctoral Research Fellowship in Disability Policy, through \#1 DRC12000002-01-00.

NBER working papers are circulated for discussion and comment purposes. They have not been peerreviewed or been subject to the review by the NBER Board of Directors that accompanies official NBER publications.

(C) 2014 by Mark Duggan, Amanda Starc, and Boris Vabson. All rights reserved. Short sections of text, not to exceed two paragraphs, may be quoted without explicit permission provided that full credit, including (C) notice, is given to the source. 
Who Benefits when the Government Pays More? Pass-Through in the Medicare Advantage

Program

Mark Duggan, Amanda Starc, and Boris Vabson

NBER Working Paper No. 19989

March 2014

JEL No. H22,I13,L1

\section{$\underline{\text { ABSTRACT }}$}

Governments contract with private firms to provide a wide range of services. While a large body of previous work has estimated the effects of that contracting, surprisingly little has investigated how those effects vary with the generosity of the contract. In this paper we examine this issue in the Medicare Advantage (MA) program, through which the federal government contracts with private insurers to coordinate and finance health care for more than 15 million Medicare recipients. To do this, we exploit a substantial policy-induced increase in MA reimbursement in metropolitan areas with a population of 250 thousand or more relative to MSAs just below this threshold. Our results demonstrate that the additional reimbursement leads more private firms to enter this market and to an increase in the share of Medicare recipients enrolled in MA plans. Our findings also reveal that only about one-fifth of the additional reimbursement is passed through to consumers in the form of better coverage. A somewhat larger share accrues to private insurers in the form of higher profits and we find suggestive evidence of a large impact on advertising expenditures. Our results have implications for a key feature of the Affordable Care Act that will reduce reimbursement to MA plans by \$156 billion from 2013 to 2022.

Mark Duggan

The Wharton School

University of Pennsylvania

1452 Steinberg Hall-Dietrich Hall

3620 Locust Walk

Philadelphia, PA 19104

and NBER

mduggan@wharton.upenn.edu

Amanda Starc

The Wharton School

University of Pennsylvania

3641 Locust Walk

Room 303 CPC

Philadelphia, PA 19104

and NBER

astarc@wharton.upenn.edu
Boris Vabson

The Wharton School

University of Pennsylvania

1400 Steinberg Hall-Dietrich Hall

3620 Locust Walk

Philadelphia, PA 19104

bvabson@wharton.upenn.edu 


\section{Introduction}

Governments often contract with private firms to provide publicly financed goods and services. While the details vary substantially, the scope of these contracting arrangements is large, representing $10 \%$ of U.S. GDP in 2008 (OECD 2011). The range of industries, goods and services is also vast, ranging from defense contractors making military helicopters to landscaping companies mowing the lawns of publicly-owned property. Private firms are also increasingly involved in social services such as charter schools (Neal 2002, Rouse 1998) and health care. Theoretically, "contracting out" could lead to improved efficiency, given that private firms have powerful incentives to control costs. Additionally, if the government contracts with multiple firms (or includes a government option), consumers may have access to more choice. This can improve consumer surplus in two ways: additional competition can lead to quality improvements and private firms may more effectively cater to heterogeneous consumer preferences.

An important example of "contracting out" can be seen in the Medicare program, which currently provides health insurance to nearly 52 million U.S. residents, with total expenditures estimated to have exceeded $\$ 600$ billion in 2013 (CMS, 2013; CBO, 2013). For most Medicare recipients, the federal government directly reimburses hospitals, physicians, and other health care providers on a fee-for-service basis. However, for 15.4 million recipients, the federal government instead contracts with private insurers and other organizations to coordinate and finance medical care as part of the Medicare Advantage (MA) program. This paper examines the MA market and asks a central question: how does the quality of private provision change as the generosity of the government contract increases? Armed with extensive data on private provision in the Medicare program, we examine the incidence of exogenous increases in plan reimbursements, in terms of the price and quality of insurance coverage, the utilization of medical care, and health outcomes.

A large body of previous research has investigated the effect of Medicare Advantage on Medicare expenditures, health care utilization, and health outcomes (Afendulis et al 2013, Landon et al 2012, Lemieux et al 2012). A related strand of research has explored how MA enrollment levels are affected by the generosity of plan reimbursement (Cawley et al 2005, Pope et al 2006). Yet, surprisingly little research has investigated how various aspects of Medicare Advantage coverage might vary with the generosity of plan reimbursement. Theoretically, one would expect plan 
payment rates to influence both the quality of coverage offered by private insurers and potentially the entry decisions of some insurers. This gap in the literature is unfortunate, given that a key feature of the recently enacted Affordable Care Act gradually lowers reimbursement to MA plans by an estimated $\$ 156$ billion from 2013-22 (CBO 2012). While the Congressional Budget Office and others have estimated that these lower payment rates will reduce MA enrollment, there is little evidence on how the number of options and the quality of coverage will change for those who remain in the program.

In this study, we aim to partially fill this gap in the literature by exploiting policy-induced variation in the generosity of MA plan reimbursement. We begin with an illustrative model-showing the impact of plan reimbursement under perfect as well as imperfect competition. Under this model, as an insurer makes its coverage more generous in response to an increase in reimbursement, more Medicare recipients are likely to enroll in the MA plan. If these marginal enrollees are more costly, then even with perfect competition, the inframarginal enrollees will not receive the full benefit of the additional reimbursement. More specifically, if an insurer receives $\$ 10$ more per month from the federal government, it cannot reduce its premium by that same amount, while keeping profits constant, if marginal enrollees are more costly. Altogether, our model formalizes how the degree of selection affects the incidence of MA reimbursement, under perfect competition. Theoretically, imperfect competition could also reduce pass-through; this factor may be material to the Medicare Advantage setting, given that the market for MA plans may be imperfectly competitive. Under imperfect competition, even if there is no difference between the marginal and the average MA enrollee, there will be less than full pass-through of benefits. We use our model to consider the factors, including plan entry, affecting incidence under imperfect competition.

Our empirical results exploit geographic variation in MA reimbursement. MA reimbursement levels are set at a county-level and are also individually risk-adjusted; the amount that a plan is paid for any given enrollee is thereby equivalent to the MA benchmark in their county of residence, multiplied by that enrollee's risk score (dependent on that individual's health status). The county benchmark, meanwhile, is largely a function of each county's per-person FFS spending levels; plans are paid more in areas with high fee-for-service spending, such as Miami, Florida, than in areas with low FFS spending, such as Minneapolis, Minnesota. However, in counties with relatively low FFS spending, benchmarks are set at a level higher than that county's FFS spending, 
otherwise known as a payment floor. In 1998, the federal government introduced this minimum benchmark to encourage plan entry in counties with low FFS spending. Initially, the payment floor was uniform across all counties. However, in 2001, the payment floor was set to be approximately $10.5 \%$ higher in counties belonging to metro areas with more than 250 thousand residents. To better understand this payment structure, we can consider an example from two comparable Illinois counties, Peoria and Sangamon, whose 2008 benchmarks were both set at the payment floor. Peoria County belongs to the Peoria, IL metropolitan area - with a population of $367 \mathrm{~K}$ - while Sangamon County belongs to the Springfield, IL MSA, with a population of just 204K. As a result, though these counties have similar per-capita FFS expenditures (\$601 for Peoria and $\$ 612$ for Sangamon), the county-level benchmark in Peoria County was $\$ 772$ per month - corresponding to the urban floor rate - versus just $\$ 699$ per month in neighboring Sangamon county - the non-urban floor rate

We investigate whether this policy-induced variation in the generosity of MA reimbursement affects the quality of insurance coverage, the utilization of medical care, as well as health outcomes. The relationship between average fee-for-service expenditures and the county-level benchmark in 2004 is shown in Figure 1. As this figure demonstrates, counties with relatively low fee-for-service spending have benchmarks that correspond to the payment floor. Furthermore, this figure documents the two different payment floors, applying to urban (metro area with population of $250 \mathrm{~K}$ or more) and non-urban (249k or less) counties, respectively. ${ }^{1}$ To estimate the impact of plan reimbursement levels, we compare counties in MSAs with a population of 250 thousand or more, which have the higher payment floors, with similar counties below this threshold. Our specifications control flexibly for both the county and the MSA population while also controlling for the level of per-capita FFS expenditures in the county. We focus primarily on counties with low per-capita feefor-service spending, in which the payment floors described above will typically be binding. We also on counties located in MSAs with populations relatively close to the 250 thousand threshold (100 - 600 thousand), so that we obtain treatment and control counties that are otherwise comparable.

Our first set of empirical results investigates the effect of the additional plan reimbursement on the number of insurers enrolling MA recipients and the HHI concentration index of MA enrollment in the county. We find that in counties with 10.5 percent more reimbursement (due to

\footnotetext{
${ }^{1}$ For reasons that we explain in more detail below, the relationship becomes somewhat hazier in the next few years, as shown in Appendix Figure 1. It is also worth noting that for the $67 \%$ of counties that belong to single-county metro areas, the county and metro populations are identical.
} 
the higher payment floor), there are on average 1.9 additional insurers and that the average HHI is lower by 1047. These effects are substantial, given that our control counties (belonging to 100-249k metro areas) have an average of 5.4 insurers and an average HHI of 4250. Consistent with this, we show that the number of plans increases and the HHI falls as the gap between the payment floor and a county's average fee-for-service costs grows. This first set of results indicates that the additional reimbursement induces more insurers to enter the MA market and that individuals enrolled in MA then have more plans from which to choose.

We next estimate the effect of the additional reimbursement on the fraction of Medicare recipients enrolling in MA. All else equal, a higher level of reimbursement would lead more Medicare recipients to be profitable for health insurers, which theoretically would lead insurers to aim for higher enrollment. Plans might achieve this by, for example, improving the quality of their coverage or by advertising more intensively. Consistent with this, we estimate that the 10.5 percent increase in plan reimbursement leads to a 7.0 percentage point increase in enrollment in Medicare Advantage HMO and PPO plans. The higher reimbursement also leads to a similar increase of 5.3 percentage points in enrollment in private fee-for-service MA plans, though these plans differ little from traditional Medicare as they do not restrict recipients' choice of providers (although they do bear financial risk).

Given evidence of higher levels of competition in markets with higher MA payments, we turn to calculating the impact on plan price and quality. Here, we find much more modest effects. For example, we find that enrollees in counties located in MSAs that are just above the population threshold do not pay significantly lower monthly premiums. Estimates that incorporate additional expected out-of-pocket costs to consumers suggest that less than one-fifth of the additional funding is passed through, allowing us to rule out pass through of more than 45 percent at the 95 percent level of confidence. These findings suggest that much less than half of the additional reimbursement is passed on to consumers financially, such as through lower premiums, deductibles, or co-payments.

Of course, plans may respond to reimbursement increases by improving the quality of medical care, rather than decreasing their enrollees' financial costs. For example, plans could contract with better providers in response to the additional revenues or cover additional services. To investigate this possibility, we use detailed individual-level data from the Consumer Assessment of Healthcare Providers and Systems (CAHPS), which contains information on plan satisfaction 
ratings, utilization, and health outcomes for approximately 160,000 enrollees per year. We find no evidence of increased patient satisfaction or increased utilization of routine, primary care, or specialist visits in urban floor counties, relative to their non-urban counterparts. Similarly, we find no impact on self-reported (overall or mental) health or satisfaction with care. Finally, while selection and composition effects could partially explain low pass-through, we find no evidence of significant composition differences across our payment threshold.

Taken together, our results indicate that the increased reimbursements paid to floor counties just above the 250 thousand threshold substantially increase the number of enrollees in Medicare Advantage, even though plan quality appears to be little changed. Not only is this inconsistent with a model of perfect competition, but it presents a puzzle even under the presumption of imperfectly competitive insurers. How could insurers increase enrollment in counties above the MSA population threshold, without making changes to plan quality? We present suggestive evidence that firms may accomplish this by advertising more aggressively in counties with higher benchmarks, with this increased advertising leading to higher enrollments. The increase in advertising spending, meanwhile, suggests that not all of the rents associated with market power are captured by insurers. ${ }^{2}$

The recently enacted Affordable Care Act instituted many changes to the Medicare Advantage program that are currently being phased in. Chief among them is a reduction in the generosity of MA reimbursement, with the magnitude of these reductions growing steadily over time. According to the Congressional Budget Office, these cuts will save the federal government $\$ 156$ billion over the 2013-2022 period (CBO 2012). Our estimates indicate that the financial incidence of these cuts will fall to a significant extent on the supply side of the market. While we cannot measure the direct impact on firm profitability, we can look to stock returns as a proxy. In April 2013, following reversals of planned cuts to the MA program, the stock market valuation of major health insurers rose substantially (see Figure 2). ${ }^{3}$ At the same time, the stock price of the largest publicly traded hospital operator (HCA) was unchanged. Consistent with the evidence that we present below, this suggests that consumer costs fall less from policy-induced increases in MA plan reimbursement than a perfectly competitive model would predict. Further, given that

\footnotetext{
${ }^{2}$ To the extent that the market for hospital or physician services is imperfectly competitive, some of the benefits of additional reimbursement may be passed through to them as well.

${ }^{3}$ Stock prices of major insurers reacted similarly-in February 2014- to reductions in the expected size of MA cuts. See Al-Issis and Miller (2013) for an examination of the effect of the Affordable Care Act on the stock prices of a broader set of firms in the health care sector.
} 
insurers, rather than providers, appear to be the primary beneficiaries of reimbursement increases, it appears that insurance operators have the predominant market power.

The paper is organized as followers. Section 2 describes the Medicare Advantage program

and Section 3 describes our theoretical framework. Section 4 describes the data on Medicare Advantage enrollment, cost, and quality along with insurer participation. Section 5 outlines our identification strategy and presents our results, and Section 6 concludes.

\section{The Medicare Advantage Program}

First introduced in 1982 as Medicare Part C, the forerunners to contemporary Medicare Advantage plans allowed consumers to opt out of traditional fee-for-service (FFS) Medicare and into private managed care plans. The federal government hoped to achieve quality as well as cost improvements by harnessing competition between private insurers (see McGuire, Newhouse, and Sinaiko 2011, for a comprehensive history). In contrast to the FFS framework used by Medicare, private Medicare Advantage plans provide care through a managed care model. Under traditional FFS, patients have substantial freedom in selecting physicians as well as treatment options, with relatively few restrictions placed on the scope of care. Under managed care, greater restrictions exist on physician access, with consumers often limited to a plan's provider network. Furthermore, many managed care plans require special approval for specialist visits and certain procedures. They may also make efforts to coordinate patient care, which could yield efficiency improvements.

\subsection{Plan Description}

While all Medicare Advantage plans must cover the services that are included under traditional Medicare Parts A and B, individual plans can differ in the supplemental benefits that they provide, such as vision or prescription drug coverage. Plans can also differ in their financial characteristics, including the premium charged and consumer co-payments (which affect the level and variance of predicted out of pocket costs). Private insurers can enter county-level markets by offering a variety of plans, and an insurer can selectively introduce a Medicare Advantage plan to certain counties and not to others. An insurer can offer multiple plans within the same county and vary the characteristics of these plans. However, Medicare Advantage plans are guaranteed-issue, and 
the insurer is required to offer coverage to all interested Medicare recipients in the counties in which a given plan is active.

Plans can also differ in the specific type of managed care framework that they utilize. All Medicare Advantage plans were operated as health maintenance organizations (HMO's) through 2003. However, following the passage of the Medicare Modernization Act, these plans could also operate as POS (point of service), PPO (preferred provider organization), or PFFS (private feefor-service). HMO, POS, and PPO plans all rely on provider networks, while PFFS plans were not required to construct networks prior to 2011. Medicare Advantage HMO plans do not allow enrollees to see physicians or hospital outside of their provider network, barring a medical emergency. POS enrollees, meanwhile, have the option of visiting physicians and hospitals outside of the network, but require explicit approval to do so. Under PPO plans, out-of-network physician visits would not require plan approval, but would entail greater cost sharing. Finally, as part of PFFS plans, enrollees would have the option to visit any physician, so long as that physician accepts the payment terms of the PFFS plan (cost sharing terms for the patient would remain the same across all physicians). Differences between these plan types could ultimately shape insurers' market entry decisions, in terms of the plan types offered within a county. For instance, given that PFFS plans are not required to form provider networks, the fixed costs of market entry for PFFS plans could be much lower than for other types of plans.

\subsection{Plan Reimbursement}

Payments to Medicare Advantage plans are based on payment benchmarks, which correspond to a given enrollee's county of residence. The benchmark payment is risk-adjusted for that enrollee's demographic and health characteristics. Originally, county-level payment benchmarks for Medicare Advantage plans were set at $95 \%$ of a county's per enrollee, risk-adjusted Medicare fee-for-service spending. CMS introduced a payment floor in 1998, primarily to encourage plan entry to rural counties. However, as a by-product, government spending on MA enrollees in many counties (particularly rural ones) came to exceed spending on similar enrollees in Medicare FFS. In 2001, CMS introduced a second payment floor, which was set at an approximately 10.5 percent premium to the existing one, and which applied only to urban counties. CMS defined a county as "urban" if the metropolitan area in which it is included had a population of 250 thousand or more. 
The relationship between a county's average per-capita fee-for-service spending and its benchmark, as of 2004, can be seen in Figure 1. As this figure shows, counties with relatively low FFS spending had benchmarks set at the payment floor. More specifically, a non-urban county with average per-capita FFS spending below $\$ 555$ per month had a floor of $\$ 555$ while an urban county with average per-capita FFS spending below $\$ 613$ had a floor of $\$ 613$. Counties with per-capita FFS spending above $\$ 613$ were in this year essentially unaffected by the payment floor while only urban counties between $\$ 555$ and $\$ 613$ are affected. As the figure shows, the magnitude of the impact of the payment floor is quite substantial for some counties. Consider an urban county with per-capita FFS spending of $\$ 500$. Its benchmark is 23 percent greater than it would be in the absence of the payment floor. The corresponding gap is considerably smaller for an urban county with per-capita FFS spending of $\$ 600$, where the floor increases the benchmark by just 2 percent.

Our analysis focuses on the 2007-2011 period, throughout which payment floors continue to be functionally (albeit not formally) present; benchmarks after 2004 were set at the highest of the previous year's benchmark (adjusted for inflation) or a county's average FFS level. As such, 2004 floor counties would have 2007-2011 benchmarks set at the inflation adjusted 2004 floor rates, so long as the inflation adjusted floor, from 2004, exceeded that county's contemporaneous FFS costs. Ultimately, over $90 \%$ of the original, 2004 floor counties remained floors in the subsequent period. The relationship between benchmarks \& a county's average per-capita fee-for-service spending, for this period, can be seen in Appendix Figure I; as expected, this relationship is largely consistent with what was observed in 2004, though it becomes somewhat less tight. ${ }^{4}$

In 2003, the Medicare Modernization Act introduced an additional component to the reimbursement mechanism, in the form of a bidding system. Beginning in 2006, if a firm placed a bid that was lower than the existing reimbursement benchmark, 25 percent of the difference got returned to the federal government. The remaining 75 percent got passed back to plans, and had to fund services not covered by traditional Medicare or be passed on to consumers. In the first year of these bids, CMS estimated that $65 \%$ of these rebates went towards part A and B cost-sharing reductions, $14 \%$ towards providing non-traditional benefits (vision, etc), $4 \%$ towards reducing part

\footnotetext{
${ }^{4}$ To the extent that a county's FFS level rose above the floor level in one or more years, its benchmark would subsequently exceed the inflation-adjusted floor. This explains why some counties in 2007 have a benchmark above the linear relationships displayed in Figure 1. Similarly, counties with non-binding 2004 floors would have subsequent rates that always exceeded the corresponding, inflation adjusted floor level, irrespective of their subsequent FFS costs. After 2004, a county can go from being floor to non-floor, but cannot go from being non-floor to floor.
} 
B premiums, and $16 \%$ towards part D benefits and premium reductions (CHS, 2006). Recent work has explored the effect of county benchmark changes on plan bids but does not consider the effects on measures of plan quality (Song et al, 2013). ${ }^{5}$

A number of papers highlight the beneficial effects of competition in Medicare Advantage, on characteristics such as premium costs (Town and Liu 2003, Lustig 2010) and out-of-pocket payment levels (Dunn 2011). Separately, a literature has examined firm entry in this market (Chernew et al 2005, Pizer and Frakt 2002, and Frakt, Pizer, and Feldman 2009), and a broad literature has considered other aspects of the program, including consumer choice (Dafny and Dranove 2008), mortality, and disparities in health care (Balsa, Cao, and McGuire 2007). Our paper adds to this literature by examining the effect of policy-induced changes in plan generosity on market structure, MA plan enrollment, and on the quality of MA coverage.

Our paper also adds to an expanding literature on the role of insurance market competition in shaping negotiations with providers (Ho and Lee 2013, Gowrisankaran, Nevo, and Town 2013), and premiums (Dafny 2010, Dafny, Duggan, and Ramanaryan 2012). Furthermore, our paper is similar in spirit to a number of papers that evaluate the impact of the Medicare program on private insurers and consumers (see Cabral and Mahoney 2013 and Starc 2013 on Medigap, Abaluck and Gruber 2011, Ketcham et al 2012, Kling et al 2012, or Einav, Finkelstein, and Schrimpf 2013 on demand in Medicare Part D, and Clemens and Gottleib 2013 on the relationship between public and private reimbursement). Finally, Gaynor and Town 2012 provide a nice summary of competition in health care markets more broadly.

\section{Theory}

This section describes the theoretical framework that informs the empirical specifications and highlights the fact that incidence depends on the degree of competition in the market as well as selection. Under perfect competition and constant marginal costs (perfectly elastic supply), we

\footnotetext{
${ }^{5}$ Song et al (2013) explore the effect of benchmark changes on plan bids. They instrument for the county benchmark with the growth of FFS spending in other counties in the state and with the national changes in benchmarks (which in dollar terms are larger for those counties with higher baseline FFS spending). However, this identifying variation is unlikely to be exogenous, given the many factors with which initial benchmark levels \& state-level FFS growth rates may be associated. One of the many outcome variables that we consider below is the plan rebate, which is three-fourths of the difference between the bid and the benchmark.
} 
expect full pass-through of reimbursements to consumers. ${ }^{6}$ However, competition may be imperfect and there may be (adverse or advantageous) selection (conditional on any risk adjustment). Just as manufacturers face upward sloping supply curves because the last plant location is not as efficient as the first plant location, insurance companies may face upward sloping average cost curves as well. If there is advantageous selection ${ }^{7}$, then the marginal Medicare Advantage consumer is sicker and more costly to insure than the average. The average cost curve traces out costs from those who value insurance the most to those who value insurance least. Under advantageous selection, the low cost enrollees have the highest valuation for Medicare Advantage plans. In this case, we should expect a pass-through rate of less than one. As the amount of the subsidy increases, Medicare Advantage penetration rates increase, and sicker consumers begin to enroll in plans. As a result a dollar increase in the subsidy must fund the health costs of the sicker enrollees in addition to providing additional benefits to existing enrollees. Figure 4 illustrates that incomplete pass-through under advantageous selection into Medicare Advantage policies. ${ }^{8}$ Let $A C_{1}$ be average costs under initial reimbursement generosity. If generosity increases by some amount $m$, there is a downward shift in the insurer's average cost curve to $A C_{2}$. If demand were completely inelastic, the price would fall from $p_{1}$ to $p_{1}-m$. However, if demand is not completely inelastic, the price will fall to some intermediate level $p_{2}$ : the incidence of the increased generosity depends on the relative elasticity of supply (determined by selection) and demand. ${ }^{9}$

Furthermore, various studies (Dafny 2010, Lustig 2010, Starc 2013) have argued that perfect competition is a poor benchmark in insurance markets, and the incidence of the MA subsidy also depends on market structure. Consider pass-through under monopoly. Figure 5 shows a downward shift of the average cost curve and assumes no selection; the marginal consumer and average

\footnotetext{
${ }^{6}$ Therefore, the reimbursement is optimal when the marginal consumer in Medicare Advantage places a value on the additional coverage provided at an amount equal to the shadow price of public funds.

${ }^{7}$ As suggested by Brown et al. (2013).

${ }^{8}$ We collapse this average out-of-pocket cost to an effective price $p$ and assume no differences in plan quality. We will relax this assumption in the empirical section and explore the relationship between contract generosity and plan quality.

${ }^{9}$ The intuition is reversed if there is adverse selection. Pass-through is greater than one because the increased subsidy serves to internalize part of the asymmetric information problem. If there is relatively little selection (and thus a flat $\mathrm{AC}$ curve) and the market for MA plans is perfectly competitive, then virtually all of the additional spending passes through to consumers in the form of a lower premium.

The intuition is reversed if there is adverse selection. Pass-through is greater than one because the increased subsidy serves to internalize part of the asymmetric information problem. If there is relatively little selection (and thus a flat AC curve) and the market for MA plans is perfectly competitive, then virtually all of the additional spending passes through to consumers in the form of a lower premium.
} 
consumer are the same. When the monopolist sets price equal to marginal revenue, the decrease in price is smaller than under perfect competition because the marginal revenue curve is steeper than the demand curve. In our example with constant marginal costs, linear demand would imply a pass-through rate of one-half, as the marginal revenue curve is twice as steep as the demand curve. Advantageous selection amplifies this effect. Therefore, both advantageous selection and imperfect competition theoretically reduce pass-through rates. Weyl and Fabinger (2013) expand this analysis to intermediate cases: the less competitive the conduct in a market is, the smaller the pass-through rate. ${ }^{10}$

In addition, more firms may enter as a result of increased plan generosity. If entry is costly, then an increase in government benefits could induce additional firms to enter. This is socially beneficial if the benefits to consumers in the form of increased competition and product variety are greater than the additional fixed costs incurred and the deadweight loss of taxation. However, if increased generosity spurs excess entry, fixed and marketing expenditures are real economic costs. A model describing the full strategic interaction of imperfectly competitive firms is outside the scope of this paper; however, we can describe the strategic decisions made by insurers.

First, the firm must decide which markets to enter. Second, conditional on being active in a market, they must design insurance products, and then set premiums for those insurance products. Finally, the firm may choose to make ongoing quality investments over the course of the year, and earn variable profits on each policy. If the discounted sum of future variable profits is higher than the fixed cost of entry, the firm enters the market. ${ }^{11}$ Therefore, in order to predict firm entry and the associated increase in competitive pressure, we are interested in a comparative static that links benchmarks to firm variable profits. This comparative static depends on four effects.

The first is the direct effect, where increased benchmarks lead to higher reimbursements for firms. The second is a price effect: for the same vector of bids, an increased benchmark means

\footnotetext{
${ }^{10}$ Similarly, Mahoney and Weyl (2013) specifically consider the case of selection markets.

${ }^{11}$ A firm $f$ may have a number of products $j$ in market $m$. The firms variable profits from that policy can be written as:

$$
\pi_{j m}=\sum_{i}\left(b_{m}+p_{j}-c_{i j m}\right) s_{i j m}
$$

where $b_{m}$ is the benchmark (which in practice is adjusted by the individual's risk score), $p_{j m}$ the plan's premium (if any), $c_{i j m}$ the cost of individual $i$ covered by plan $j$ in market $m$, and $s_{i j m}$ the probability that the same consumer purchases the plan. In order to get firm-level variable profits in a given market, aggregate over all plans within a market offered by the firm and subtract any fixed or sunk cost of entry.
} 
a lower price for consumers, depending on the pass-through rate. ${ }^{12}$ Third, there is a cost effect, where higher benchmarks could change the nature of selection within the market. For example, increasing penetration rates may lead to firms attracting sicker consumers, increasing costs, if there is advantageous selection in the market. Finally, there is a market power effect, in which high benchmarks may lead to more entry. As more firms enter, consumers have access to more plans that may prove to be closer substitutes, driving down markups. The overall effect of more generous plan reimbursement is ultimately an empirical question.

\section{Data}

We use a number of administrative datasets from CMS (Centers for Medicare \& Medicaid Services) and from HCUP (Healthcare Cost \& Utilization Project) that contain MA plan enrollment levels, plans' financial generosity, measures of plan quality and patient utilization, government payment amounts to Medicare Advantage plans, and FFS spending levels per enrollee. We extract information on plan characteristics from a variety of CMS datasets, covering such dimensions as insurer identity, plan type, plan financial characteristics (including premium and out of pocket costs), and plan quality measures. We construct measures of MA enrollee composition at a plan, county, as well as year level, using CAHPS survey data, Medicare enrollment data (from the denominator files), as well as hospital discharge data. These data are nationwide in scope, covering more than three thousand US counties. We have annual county-level data on the number of insurers, the HHI index, and MA enrollment (separately by HMO, PPO, and PFFS) from 2007 through 2011 along with data on plan characteristics (such as premiums, out-of-pocket costs, and Part D coverage), and individual-level data on MA plan ratings for these same years.

We initially differentiate between three types of counties - those with monthly per-capita FFS spending below $\$ 662.32$ in 2007 , those between $\$ 662.32$ and $\$ 732.04$, and finally those above \$732.04. For the first group, for any given level of FFS spending, the benchmark is typically 10.5 percent higher in urban counties than in non-urban counties and is set at the payment floor. For the third group, the benchmarks are essentially the same in each of the two types of counties for

\footnotetext{
${ }^{12}$ A higher benchmark need not change the competitive environment or optimal prices; increased benchmarks may simply affect firm profits by increasing quantity, as decreased premiums may increase Medicare penetration rates, and, therefore profits.
} 
any given level of FFS spending. And for the second group, the gap in benchmarks between the two counties declines linearly from about 10.5 percent at per-capita FFS spending of $\$ 662.32$ to 0 by $\$ 732.04$. Urban counties in this group typically have their benchmarks set at the payment floor while non-urban counties do not.

Figure 1 shows the relationship between average fee-for-service expenditures and county benchmarks for the three types of counties as of 2004, while Appendix Figure I presents the comparable relationship for $2007^{13}$. As these figures show, the effect of being designated an urban county (in a metropolitan area with 250 thousand or more residents) is largest for those with average fee-for-service spending below $\$ 662$ and this effect declines steadily from that threshold to the threshold of $\$ 732$, at which point the floor no longer binds for urban counties. Table 1 provides summary statistics for all counties and then separately for each of these three types of counties. As the table shows, both benchmarks and average per-capita FFS expenditures are substantially higher for the third group than for the second or first groups. Additionally the average population both of the individual counties and of the metropolitan areas in which they are included - is highest among those above the $\$ 732$ threshold and lowest in those below the $\$ 662$ threshold.

It is worth noting that a county's floor status can change from one year to the next. More specifically, a floor county in which per-capita FFS spending grows relatively rapidly may move out of the floor category. This is of course more likely for counties close to the kinks in the schedule displayed in Figure 1. For example, among non-urban counties with FFS expenditures from 600 to 662 in 2007, around seven percent are no longer "floor counties" three years later in 2010. In contrast, just three percent of non-urban counties with FFS expenditures below 600 in 2007 are no longer floors as of 2010 . The patterns are similar for urban counties, with those closer to the kink in 2007 more likely to shift to non-floor status thereafter. Rather than redefining the floor "treatment" each year, we use a county's 2007 FFS expenditures and its status as an urban or nonurban county in that year as our primary source of variation in the generosity of plan reimbursement below. Our analyses explore the effect of this reimbursement generosity from 2007 through 2011.

In our first set of analyses, we include all 3028 counties with non-missing data. However, because we use the urban / non-urban threshold as a key source of identification, we primarily focus

\footnotetext{
${ }^{13}$ As of 2007 , a number of of counties-but fewer than $10 \%$-no longer have benchmarks determined in the same manner as in 2004. The reasons for this are described in Section 2.2.
} 
on counties located in metropolitan areas that are relatively close to the 250 thousand population threshold so as to have a more comparable set of counties. More specifically, in subsequent analyses, we restrict to counties belonging to metropolitan areas with populations between 100 thousand and 600 thousand. The population range is set larger above the threshold because the density of metropolitan area populations is somewhat thicker in the range below the threshold than above. These criteria yield a sample of 576 counties, with 304 below the population threshold and 272 above. These counties are included in 280 metropolitan areas, with approximately half of the metro areas having just 1 county, 20 percent having exactly two counties, and the remaining 30 percent having between 3 and 6 counties. As we explain in more detail below, in most specifications, we further restrict attention to the 348 counties in this group of 576 with sufficiently low fee-forservice spending to be fully affected by the payment floors displayed in Figure 1.

\subsection{Plan Enrollment Data}

We obtain Landscape files from CMS on Medicare Advantage enrollment levels for the combination of the following: county, month, insurer, and the insurance package offered by that insurer (which has the technical term contract). Our final dataset is at the county-year-insurance contract level. For any given year, we exclude contracts with fewer than 10 enrollees. In addition, we obtain information on county-year level Medicare enrollment levels, which allows us to calculate Medicare Advantage's share of each county's Medicare population. For counties with fewer than 10 MA enrollees, this number is not reported. Given the small number of counties in our analysis sample

missing this data (e.g. just 11 out of 576 in 2007), our results are not sensitive to whether we exclude these counties from our sample or assume that MA enrollment there is equal to 0 .

Across all counties nationwide with MA enrollment exceeding ten, the average number of insurers offering an MA plan is 4.8 and the average HHI concentration index is 4,961. For our restricted sample, the corresponding averages are 6.2 and 3,937, respectively. These market measures treat PFFS, HMO, and PPO types of Medicare Advantage similarly. We compile a list of the most active insurers, based on the number of county-years in which they operate from 2007 through 2011, and also break out each firm's activity by county type as in Table I. We present these statistics in Table 2 and show that Humana is the most active MA insurer, in terms of county-years in which it is present (comprising nearly 80 percent of all possible markets) and in terms of the 
number of enrollees it covers (across our restricted sample, it covers about a quarter of all those in MA). Interestingly, it is the insurer with the greatest stock price response to MA reimbursement increases, as displayed in Figure 2.

\subsection{Plan Characteristics Data}

To measure plan financial characteristics, we draw on plan-year level data from the CMS landscape files and metrics of premium levels, the availability of drug coverage, and mean drug deductibles and copayments (for the plans that offer this coverage). ${ }^{14}$ We obtain data on consumer out-of-pocket costs at a plan-year level as compiled by CMS. These figures are featured as part of the Medicare Compare database, and, therefore, are likely to be salient to consumers. The database includes information on overall expected out-of-pocket costs and also separates these costs into individual components (such as Part B premiums, inpatient hospital costs, and prescription drugs). Further, these data break down expected out-of-pocket costs across different demographics-by age as well as self-reported health status. For example, the database provides an expected out-of-pocket cost for a 65-72 year old in excellent health, enrolled in a given insurance contract. Altogether, we average these estimates-across demographic groups-to construct a single composite metric. There is no geographic variation in this data-it does not account for cross-region differences in practice patterns or price levels-so it provides a valuable standardized measure of plan generosity.

If insurers bid below the benchmark, they must devote a part of the difference to improving consumer benefits in the form of a rebate of added benefits. As noted, the bid denotes the insurer's estimated cost of providing traditional Medicare coverage to an enrollee with an average risk score. The rebate amount, meanwhile, equates to $75 \%$ of the difference between the bid amount and the benchmark, in those cases where the benchmark exceeds the bid (CHS, 2006). As such, we examine the impact of benchmark differences on rebate amounts, which we obtain from CMS data files at an insurer-plan type-county-year level.

In some cases, plans allocate rebates towards decreasing the Part B premium paid by consumers. Plans could also allocate this rebate towards reduced cost-sharing or supplementary

\footnotetext{
${ }^{14}$ We also obtain information from CMS on the parent companies operating each specific insurance plan, as well as the type of coverage offered (HMO/HMOPOS, PFFS, or PPO). Following the literature, we consider the plan with the lowest plan ID to be most representative of the insurance contract as a whole (Hall 2007 and Nosal 2012). In matching contract enrollments to individual plan characteristics, we match enrollments to the characteristics of the lowest plan ID within the contract.
} 
benefits like drug coverage. When the estimated cost of supplementary benefits exceeds the rebate amount, plans can charge consumers an additional premium: there exist many plans that receive rebates, yet simultaneously charge a premium. In Table I, we present the average financial characteristics of plans across different sets of counties, including urban floor and non-urban floor counties in the population range of interest. The results indicate that plans' financial generosity in urban floor counties is no greater, on average, than in the non-urban counterparts. These numbers suggest that higher payments to plans within urban floor counties are not getting passed on to consumers, at least financially.

\subsection{Plan Quality Data}

As measures of plan quality, we rely on CAHPS survey data, which contains enrollees' ratings of plans, self-assessments of health status, and other measures of plan experience, such as selfreported number of physician visits. The CAHPS survey is administered yearly, and covers every Medicare Advantage plan that is at least a year old (including HMO, PPO, as well as PFFS plans). As part of the survey, 600 individuals from each MA contract are selected for questioning (if a contract has fewer than 600 enrollees, then all of its enrollees are selected). While 600 are selected for questioning, fewer respond (non-response rate is around $25 \%$ ).

We have obtained the CAHPS data at an individual respondent-level, covering around 160,000 MA enrollees annually, for the years 2007-2011, The data identifies the insurance contract in which each survey respondent is enrolled, along with that respondent's demographic characteristics such as county of residence, age, race, and education. In addition, the data contains the respondent's answers to each of the survey questions. Even with our sample restrictions, we are left with 81,890 person-year observations across the CAHPS data. In Table 6, we present the average levels of CAHPS indicators within different sets of counties, including urban floor and non-urban floor counties. We find that measures of plan quality and utilization appear to be similar across these counties.

As an alternative measure of the quality and composition of care within plans, we also make use of hospital discharge data from HCUP's National Inpatient Sample (NIS), for the years 2007-2010. The NIS contains discharge-level data for every single visit made to a hospital, from $20 \%$ of all hospitals from over 40 states. The data in the NIS is at an individual-discharge level, 
and was separately submitted to the NIS by each participating state. As such, the heterogeneity in what states track or turn-over also finds its way into the NIS. Only a fraction of states in the NIS, 16 in total, offer the specific information required for our analyses-county identifiers and identifiers differentiating Medicare FFS from Medicare Advantage patients (incidentally, these states contain $59 \%$ of MA enrollees). ${ }^{15}$

\subsection{Identification Strategy}

We exploit variation in the Medicare Advantage benchmark formula that leads urban floor counties to have benchmarks that are approximately $10.5 \%$ higher than similar, non-urban floor counties. As shown in Appendix Figure 1, both urban and non-urban counties with per-capita FFS expenditures of $\$ 662$ or less in 2007 typically had benchmarks set at the urban or non-urban floor. In contrast, the payment floor did not bind in counties above $\$ 732$ in per-capita FFS spending. Urban counties between these two thresholds usually had benchmarks at the urban floor while the non-urban floor was not binding in comparable counties in metropolitan areas with a population of less than 250 thousand.

Our key sources of variation are the urban population threshold and a county's per-capita level of fee-for-service expenditures. We begin by estimating the effect of urban status on the level of benchmarks and then proceed to estimate the effect on market outcomes such as the number of insurers and the HHI concentration index along with measures of plan quality such as plan premiums and enrollee satisfaction with care. We control flexibly for a county's per-capita level of FFS expenditures and for both the county and metropolitan area population when estimating specifications of the following type:

$$
Y_{j t}=b_{0}+b_{1} * F F S_{j, 2007}+b_{2} * \operatorname{Urban}_{j}+f\left(\text { CountyPop }_{j, 2007}\right)+g\left(\text { MetroPop }_{j, 2007}\right)+g_{t}
$$

In this equation, our coefficient of particular interest is $b_{2}$, which represents our estimate of the average impact of urban status on outcome variable $Y_{j t}$. One concern with this equation is that there

\footnotetext{
${ }^{15}$ We should note that county identifiers contained in the NIS all denote the location of the hospital, rather than of the patient's original county of residence. As MA reimbursement is based on patients' county of residence, this results in some measurement error. However, the extent of this error could be modest, as evidence suggests that the vast majority patients use hospitals in their home counties (for example in California's discharge data, hospital and patient county correspond approximately $95 \%$ of the time).
} 
may be other factors associated with urban status - being part of a relatively large metropolitan area - that are not adequately captured by our controls for county and metropolitan area population and fee-for-service expenditures. This concern is to some extent reduced by focusing on a smaller and more comparable set of counties that are close to the 250 thousand threshold. To probe further on this potential concern, we estimate this specification with each of the three set of counties - those

"fully treated" by the urban status, those "partially treated" and those "untreated." If we were to estimate a large effect of urban status on the benchmark for counties with high per-capita FFS expenditures, this would suggest that some other factor is driving the estimate.

We also estimate specifications in which we consider those counties with FFS costs in 2007 that put them above the non-urban floor threshold but below the urban floor. Urban counties in this per-capita FFS range are essentially partially treated. This is close to a full treatment for counties close to $\$ 662$ in per-capita FFS expenditures and declines linearly to 0 for those counties at \$732. We therefore define a variable GAP that captures this partial treatment as the (absolute value of the) difference between the county's 2007 FFS spending and $\$ 732$ while dividing this difference by $\$ 70$.

$$
\begin{aligned}
Y_{j t}= & b_{0}+b_{1} * \operatorname{FFS}_{j, 2007}+b_{2} * \operatorname{Urban}_{j}+b_{3} * G A P_{j} \\
& +b_{4} * \operatorname{Urban}_{j} * G A P_{j}+f\left(\text { CountyPop }_{j, 2007}\right)+g\left(\text { MetroPop }_{j, 2007}\right)+g_{t}
\end{aligned}
$$

We estimate the first specification above for each of the three sets of counties and estimate the second specification for counties above the $\$ 662$ threshold. Our analysis focuses on the period from 2007 through 2011.

\section{$5 \quad$ Results}

\subsection{The Impact on County Benchmarks}

Table 3 summarizes the results from several specifications that explore the impact of a county's urban status on its monthly Medicare Advantage benchmark. The specification listed in the first column includes observations for each year from 2007 through 2011 for all counties with monthly 
fee-for-service spending below $\$ 662.32$. The specifications also control (with a linear and quadratic term) for both the county population and the metropolitan area population along with monthly fee-for-service expenditures. Standard errors are clustered at the metropolitan area level given the level of variation of the URBAN indicator. The statistically significant estimate for the coefficient on the URBAN indicator implies that during this five-year time period, the average difference in monthly benchmarks between urban and non-urban counties in this group was about $\$ 72$. This estimate is virtually unchanged in the next column when we restrict attention to the subset of counties in metro areas with populations between 100 and 600 thousand. In both specifications, there is a small though statistically significant estimate on the coefficient for FFS expenditures. This reflects the fact that, as described above, counties close to the threshold are more likely to have fee-for-service spending above the payment floors in one or more subsequent years (causing some county benchmarks to eventually exceed the payment floor).

The next two columns summarize a companion set of specifications for counties with feefor-service expenditures between $\$ 662$ and $\$ 732$. As shown in Figure 1 , in this range, status as an urban county results in a partial treatment as the gap between the urban and non-urban benchmarks is only a fraction of that for those in the lower FFS range. And consistent with this, the point estimates for the URBAN indicator are significantly positive though much smaller than for the previous samples, suggesting on average an increase of $\$ 23$ in the monthly benchmark. In these specifications, the coefficient for the FFS expenditures variable is large and highly significant, which makes sense given that - at least for non-urban counties - higher FFS expenditures directly translate into a higher benchmark.

In columns five and six, we summarize the results for counties with per-capita FFS expenditures above $\$ 732$ per month. For this set of counties, the URBAN indicator should have little impact on the benchmark, as shown in Figure 1. Consistent with this, column five shows an estimate of just $\$ 3$, which is statistically insignificant. For the narrower sample, the URBAN indicator coefficient is actually negative and marginally statistically significant. In these two specifications, the coefficient estimate for FFS spending is slightly above 1, reflecting the direct relationship between FFS expenditures and the benchmark shown in this expenditure range as shown in Figure 1.

In the final two specifications, we estimate specifications similar to (2) above in which we 
include counties above the $\$ 662$ threshold, thus combining the second and third groups. In both specifications, the URBAN indicator is small in magnitude and statistically insignificant. However, the interaction of the URBAN indicator with the GAP variable described above is close to $\$ 50$ in both cases and highly statistically significant. This provides further evidence that the baseline level of per-capita FFS expenditures is a strong predictor of the benchmark even for those counties above the non-urban floor threshold.

Taken together, the results in Table 3 demonstrate that URBAN status is a powerful predictor of MA benchmarks for counties with FFS expenditures below both the urban and non-urban floors. Additionally, the results are fairly similar when we consider the full sample or restrict attention to the subset of counties in metro areas with populations close to the 250 thousand threshold. In the subsequent sections, we focus primarily on counties with per-capita FFS expenditures below the non-urban threshold in 2007 and with metro populations between 100 and 600 thousand. We do this so as to focus on the counties for which the URBAN status "matters most" and to consider a more comparable set of counties.

\subsection{Market Structure}

We next explore the effect of the policy-induced increase in MA plan reimbursement on two measures of market structure - the number of insurers and the HHI concentration index. As our model above suggests, increases in the generosity of reimbursement may cause additional firms to enter the MA market and incumbent firms to increase the quality of their product in response. Here, we consider counties in the first group described above, with FFS expenditures per enrollee below $\$ 662$ in 2007. For this group of counties, the average number of insurers offering an MA plan during the 2007 through 2011 period was 6.2 and the average HHI concentration index 3,937 (measured on a 10,000 scale). We once again control for both county population and metropolitan area population (with both a linear and quadratic term) and for average per-capita FFS expenditures in 2007. In contrast to the previous set of analyses, one would expect the population measures to be an important determinant of our outcome variables.

The first specification summarized in Table 4 considers the effect of URBAN status on the

number of insurers. The point estimate of 1.92 for the URBAN indicator variable equates to more than 30 percent of a county's mean number of insurers, for our analytic sample. This estimate 
is highly significant with a t-statistic of 3.6. This same column reveals that there is a strong relationship with the county population (and the estimate for the URBAN indicator is robust to including a cubic and a quartic in this county population measure). Interestingly, the population of the metropolitan area has little additional relationship with this outcome variable. The significantly negative point estimate of -.618 for the per-capita FFS expenditures variable suggests that fewer insurers enter as a county's fee-for-service expenditures gets closer to the threshold. This makes sense as the gap between the plan reimbursement and FFS expenditures is declining in that measure (as shown in Figure 1). Thus just as insurers appear to respond to the greater profit opportunities caused by the higher floor for urban counties, they also respond to the larger incentives in the counties with very low fee-for-service spending.

The second specification yields a similar picture by considering the effect of URBAN status on the HHI concentration index. Counties in metropolitan areas above the URBAN threshold are significantly less concentrated, with the point estimate of -1047 representing more than onefourth the mean HHI in our analysis sample. This is approximately equal to the HHI decline that would occur when increasing from 4 to 7 equally sized insurers (though the actual impact is clearly different given an average HHI of almost four thousand in our sample). Consistent with this, the HHI increases as FFS spending rises and the gap between this and the payment floor declines. As expected, the other point estimates in column 2 have the opposite sign to those for the previous specification given that here a larger number represents fewer insurers operating.

Columns one and two of table four suggest that the additional reimbursement available to plans in counties with the URBAN designation leads to more entry and a reduction in concentration. The next three columns identify whether and to what extent the additional reimbursement leads to more MA enrollment. The third column shows that the fraction of Medicare recipients enrolled in Medicare Advantage HMO or PPO plans increases by 7 percentage points as a result of the greater reimbursement, while column four shows a corresponding increase of 5.3 percentage points in the share enrolled in MA private fee-for-service plans. Both estimates represent nearly 75 percent of the sample means and thus our findings here suggest that the policy-induced increase in plan reimbursement leads to a Medicare Advantage enrollment increase that is substantial. It is also worth noting that - for both plan types - enrollment is declining in the level of per-capita fee-forservice expenditures. This evidence, coupled with the estimates for the URBAN status indicator, 
demonstrate that financial incentives have a powerful impact both on insurer entry and on the fraction of Medicare recipients enrolled in MA plans. This effect is due to both increased enrollment in plans that tend to exist in all counties and in marginal entrants.

In a companion set of specifications not summarized here, we investigated the relationship between these outcome variables and URBAN status as in equation (2) above for the sample of counties above the $\$ 662$ threshold in per-capita fee-for-service expenditures. Our results there are broadly consistent with those displayed in Table 4 for counties below this $\$ 662$ threshold, suggesting that the extra reimbursement resulting from URBAN designation for those counties "partially treated" by it leads to more entry, lower concentration, and an increase in Medicare Advantage enrollment.

\subsection{Financial Characteristics of Plans}

We next consider how the financial generosity of MA coverage varies with the additional policyinduced reimbursement. As discussed in our theoretical framework above, insurers may respond to the higher benchmarks in URBAN counties and to the resulting increase in competition by reducing their premiums or out-of-pocket costs or by offering additional services. To test this possibility, we begin by exploring the relationship between URBAN status and the monthly MA plan premium, which has an average value of approximately $\$ 30$ in our analysis sample. This premium data is available at the county-plan-year level, and our county-year measures are enrollment weightedaverages. As shown in the first column of Table 5, the point estimate for the URBAN indicator is very small in magnitude (-0.76) and statistically insignificant. This suggests that despite the substantially higher benchmarks in urban counties, MA enrollees do not benefit in the form of much lower premiums.

In the second column we consider the effect on the amounts that insurers allocate toward supplemental Medicare services through the rebates they are provided by CMS (if and when their bids fall below the benchmarks). We only have rebate data for 2007 through 2010, and so our analysis sample is 20 percent smaller as a result. But consistent with our estimate for the premium measure, our results provide little evidence to suggest that benchmarks that are 72 dollars higher per month lead to substantial additional benefits to enrollees. The point estimate of 3.594 represents about 5 percent of the additional reimbursement and we can rule out an increase in the rebate of 
more than 14 dollars (less than one-fifth of the additional reimbursement) at the 95 percent level of confidence.

In the third column, we investigate the effect on out-of-pocket costs (OOPC). To the extent that an insurer responds to the additional reimbursement by, for example, reducing deductibles or offering supplemental services such as vision coverage, it would be reflected in this measure. This measure weights by MA enrollment, and the average OOPC in our analysis sample is approximately $\$ 383$ per month. The point estimate of -10 for the URBAN coefficient is statistically insignificant. With this point estimate, we can rule out an out-of-pocket cost reduction of more than 31 dollars per month (about 40 percent of the benchmark increase) at the 95 percent level of confidence.

In the fouth column, the outcome variable is a measure of total costs, based on the sum of premiums and out-of-pocket costs indicators (rebates are not included to avoid double counting). The statistically insignificant point estimate of -10.78 suggests that less than one-sixth of the additional reimbursement is passed on to consumers and we can rule out a benefit of more than 33 dollars (45 percent of the benchmark effect) at the 95 percent level of confidence.

As described above, the magnitude of the gap between a county's per-capita FFS expenditures and the payment floor is significantly positively related with the number of insurers operating and with total MA enrollment. However, the estimate for the FFS expenditure coefficient in the premium, plan rebate, and out-of-pocket cost specifications suggest very little link with the generosity of coverage, which also suggests limited pass-through. In fact, the significantly negative point estimate for this variable in the OOPC specification suggests that - as the gap between the floor and FFS expenditures grows - out-of-pocket costs actually increase. This could occur if, for example, marginal entrants provide less generous coverage. Adding up the premium and OOPC measures of financial generosity, our results provide little evidence to suggest that the larger gaps that lead to more insurer entry and more MA enrollment are associated with better coverage on this dimension.

In the fifth column, we consider the provision of drug coverage and - consistent with the previous measures - find little evidence that this benefit is more likely to be offered by plans in urban counties, as the point estimate on the URBAN indicator is actually negative. And as with the OOPC variable, Part D coverage seems if anything to be less generous in counties with lower FFS reimbursement, where more insurers enter. This could once again reflect marginal entrants 
being less generous than incumbent firms on this dimension.

Taken together, the results in this section suggest that the additional plan reimbursement for plans in URBAN counties does not translate into more generous benefits for Medicare Advantage recipients. Similarly, a larger gap between the payment floor and the county's fee-for-service expenditures is also not associated with increased financial generosity. These results are to some extent surprising given that both of these variables have a powerful impact on insurer entry decisions, the concentration of the market, and on total MA enrollment. But the possibility of course remains that MA plans are improving quality on other dimensions not captured by these financial variables, such as the quality or breadth of provider networks, which motivates the analyses in the next section.

\subsection{Quality Characteristics}

Higher MA reimbursements could also be passed on to consumers in the form of quality improvements. To identify possible changes to the quality of health care coverage (as distinct from the financial measures considered above), we use respondent-level survey data from the CAHPS, for 2007-2011. These data contain information on respondents' counties of residence, allowing us to examine the relationship between county-level reimbursement variation and the measures included in the CAHPS. We have nearly 82 thousand person-year level observations for the counties in our analysis sample over this five-year period.

We examine the impact of additional plan reimbursement on respondents' overall ratings of plan quality along different dimensions: health care received, the primary care provider, specialists seen, and the plan overall. We run our results on data aggregated to a county-year level, while restricting to counties in the 100-600k metro population range, with 2007 FFS values below the floors. The main results are displayed in Table 7 . We find no significant relationship between a county's urban status and each of these rating measures. Using the approach introduced in Kling et al (2007), we calculate standardized treatment effects, to examine whether urban status has an impact on these ratings measures, as a collective. These results also indicate no significant relationships between higher MA benchmarks and plan ratings.

We also consider the impact on measures of utilization and outcomes contained in the CAHPS, such as number of specialist visits, number of personal MD visits, and self-reported health 
statuses. To the extent that additional reimbursement leads plans to restrict care less or improve health more, it could be captured by these estimates. These results, which are presented in Table 8, provide no evidence of a significant relationship between urban status and utilization or outcomes, across the counties in our sample.

In Table 9, we examine possible impact on other measures of utilization, using discharge data from the National Inpatient Sample (NIS). Throughout these analysis, we restrict to an analogous set of counties, and run specifications that include hospital fixed effects. These analyses include both MA and FFS Medicare recipients and essentially explore whether the gap in care between FFS and MA is significantly different in urban counties, as opposed to non-urbans. To the extent that, for example, plans use the additional reimbursement to allow patients to stay in the hospital a bit longer or obtain more intensive treatment, these specifications could capture it. The key independent variable throughout is the interaction term between MA status and the urban status of the enrollee's county. Altogether, results are consistent with those from the CAHPS, and show no significant association between the higher benchmarks in MA counties and measures such as length of stay and number of procedures.

It is worth noting that these results on quality and intensity of care could be biased if the increase in MA enrollment that we find in urban counties leads to a significant change in the composition of enrollees. If, for example, MA plans in urban counties had patients who were sicker (or healthier) on average, then we might estimate a significant difference even in the absence of an actual one. This motivates our analyses in the next section.

\subsection{Compositional Effects}

We do not find evidence of increased reimbursements being passed through to consumers in the form of plan quality or treatment changes. However, our results could be biased by reimbursementdriven changes to enrollee composition within Medicare Advantage. As we showed in Table 4, the 10.5 percent increase in benchmarks for floor counties resulting from urban status leads to a substantial increase in MA enrollment. As such, we test for possible compositional changes to MA enrollment, which could accompany these increases to enrollment.

Using data from the CAHPS, we restrict to counties in the 100-600k metro population range, with FFS values below the floors. We then compile demographic and health metrics for 
enrollees in urban and non-urban counties, respectively. As shown in Table 10, we do not find substantial differences in age, gender, race, or in other utilization measures across enrollees in these counties. Of course, this does not rule out the possibility of unobserved differences between the marginal and average MA enrollee. In Table 11, we consider an additional metric-the mean risk score of MA enrollees-to test for possible reimbursement-driven changes to enrollee composition. These results also do not provide any evidence of changes to selection, as a result of increased reimbursement.

These results from the CAHPS are reinforced by analyses from New York State Medicare Denominator Data, for 1998-2003. This period encompasses a 2001 policy change-the introduction of a differentiated floor for urban counties. Previously, there was a uniform floor applying across all counties. Using the exogenous reimbursement variation resulting from the introduction of this floor, we test for impact of reimbursement on MA enrollees' demographic characteristics. In doing so, we find no evidence of changes to MA enrollee composition (overall, as well as among the subset newly eligible for Medicare \& MA enrollment). ${ }^{16}$ These results are displayed in Table 12.

\subsection{Advertising and Firm Returns}

Our empirical results show that larger subsidies to Medicare Advantage plans lead to significantly more insurers operating and to less concentrated insurance markets. Furthermore, more generous subsidies lead to higher Medicare Advantage penetration rates. Given these two facts, it would be natural to assume that the higher subsidies are passed on to consumers in the form of lower premiums, OOPC, or higher quality. Our empirical results do not support this conclusion. The exogenous $\$ 72 /$ month disparity in plan benchmarks across our population discontinuity is not accompanied by significant differences in premiums, out-of-pocket costs, or rebates. While our estimates are somewhat imprecise, we can rule out increased in overall generosity of $\$ 33 /$ month or more, and thus can reject that more than 45 percent of the subsidy is passed on to consumers at a confidence level of 95 percent. The point estimates suggest pass-through of just 15 percent.

These results could still be consistent with a perfectly competitive market if other measures

\footnotetext{
${ }^{16}$ In a complementary study, Cabral et al (2014) examine the effect of this new payment floor on premiums and other measures of plan quality. It is worth noting that during this period, MA enrollment was much lower than in more recent years, and just one-in-eight counties had one or more MA plans operating in each year from 1998 through 2003.
} 
of plan quality increased substantially or if enrollee composition changed significantly as a result of advantageous selection. However, our results utilizing the CAHPS \& MA Risk score data do not support either of these hypotheses. Additional analyses using the Medicare denominator file (see Table 12) also indicate limited advantageous selection. ${ }^{17}$ Given low pass-through of benchmarks to consumers and limited evidence of meaningful selection on the margin, we argue that perfect competition is a poor benchmark for this market. While higher margins seem to stimulate competition, competition has a limited effect on the price and quality of MA plans.

Yet imperfectly competitive firms must also compete for consumers. The increase in the number of plans sold indicates that something must induce higher participation rates. We therefore explore whether strategic advertising may drive enrollments. In order to calculate the impact of benchmarks on marketing, we utilize data on TV spot advertising from Kantar Ad\$pender . Kantar tracks spending at the insurer line of business-DMA level. We keep only Medicare products and aggregrate spending to the DMA level; there are 210 DMAs and we observe four years of data, giving us 840 total observations. Here we include all counties because the DMA boundaries do not line up neatly with the county and MSA boundaries in our analysis sample. The outcome of interest is advertising spending per Medicare enrollee in a DMA. We regress this variable on a number explanatory variables, including average benchmarks and FFS spending. We average our measure of benchmarks to the DMA level using the number of Medicare enrollees in a county as weights. Because our identification strategy relies on county-level benchmarks rather than the urban population threshold described above, these results using advertising data at the more aggregated DMA level should be viewed as suggestive, rather than causal.

Table 13 presents the results. In the first specification, we regress spending per enrollee on the average benchmark, year fixed effects, population, and population squared. The relationship is positive, but statistically insignificant. However, benchmarks are likely to be correlated with FFS costs. The second specification regressed spending per enrollee on FFS costs; the coefficient is negative and significant, indicating that firms advertise less in areas with expensive enrollees (Aizawa and Kim 2013 show that advertising may drive advantageous selection). The third specification controls for FFS costs and benchmarks. In this specification, we see a strong positive relationship

\footnotetext{
${ }^{17}$ While this is true of the margin we examine, there is evidence of advantageous selection in Medicare Advantage on the whole (Brown et al 2013).
} 
between benchmarks and advertising: a $\$ 100$ increase in the average benchmark is associated with a $\$ 5$ increase in advertising spending per Medicare enrollee. The results are similar in the fourth specification, which controls for an index of advertising prices. ${ }^{18}$

Our results indicate that higher benchmarks are associated with higher levels of advertising. The point estimates suggest that moving from the twenty-fifth to seventy-fifth percentile of the average benchmark is associated with a doubling in advertising spending. ${ }^{19}$ The effects are large in magnitude, and we feel they can rationalize much of the expansion of MA plans in urban counties. Much of the additional advertising can be attributed to spending by large firms with a presence in most markets, rather than marginal entrants: Humana's spending increases by just over $\$ 1$ per Medicare enrollee per year with each $\$ 100$ increase in the monthly benchmark. Assuming a 20\% Medicare Advantage enrollment rate, this implies that firms are spending $\$ 17.50$ per additional enrollee per year in urban floor counties relative to rural floor counties with the same level of FFS spending. This additional spending can help justify strong relationship between the URBAN dummy and MA penetration rates. Furthermore, these results provide evidence that increased benchmarks need not accrue to insurers, but may flow to other players in the supply chain. Other work has shown a similar pattern, with rents accruing to insurance agents and brokers (Starc 2013).

Despite dissipation of some rents through marketing costs, it is plausible that insurers also capture part of the increased benchmarks. Figure 2 shows dramatic increases in stock prices for the four publicly traded health insurers with the most MA enrollment (Humana, United, Cigna, and Aetna) as a result of a surprisly large increase in benchmarks on April 1, 2013. A simple pre-post comparison of market capitalization for these four firms, which accounted for about 44 percent of MA enrollment at the time of the policy change, indicates a market capitalization increase of approximately $\$ 2.7$ billion. The announced benchmarks represented an increase of approximately 5.6 percent relative to what otherwise was specified by legislation. Multiplying this percentage by our estimate of baseline MA revenues for each insurer (calculated by multiplying enrollment weighted benchmarks for each insurer by the average risk score of its enrollees) yields an estimated increase in annual MA revenue of about $\$ 2.9$ billion.

\footnotetext{
${ }^{18}$ We use the primetime SQAD points (and SQAD points squared) as our measure of advertising costs. See https://www.lib.umn.edu/faq/6521 for more information.

${ }^{19}$ Our results are suggestive that the causal effect may be even larger, as seen in columns 3 and 6 . However, the regressions are at the DMA-year level, and do not allow us to exploit the identification strategy using only counties with populations between 100,000 and 400,000.
} 
It is important to note that investors apparently did expect a significant increase in benchmarks around this time. For example according to Humana's press release, the firm had expected a 4.4 percent increase in benchmarks instead of 5.6 percent. If one assumes that this also accurately captures the assumptions of investors, this would suggest that just $\$ 0.62$ billion of the $\$ 2.9$ billion increase in annual MA revenues was a surprise. Using a discount rate of 5 percent, this implies an increase in the present value of MA revenues of approximately $\$ 12.4$ billion. Combining our estimate of a $\$ 2.7$ billion increase in market capitalization with the $\$ 12.4$ billion increase in the present value of MA revenues, we estimate that 22 percent of the increase in benchmarks is passed through to insurers in the form of higher profits. Of course, the precision of this estimate is necessarily more speculative than our estimates relating to consumers. But the sharp reaction of health insurer stock prices to changes in the level of MA reimbursement strongly suggests that insurers capture much of the benefit of policy-induced increases in plan reimbursement. ${ }^{20}$

Our estimates and back of the envelope calculations indicate that, at most $50 \%$ of increased reimbursement goes to consumers and approximately $22 \%$ goes to insurers. Our advertising results suggest that some of the increased expenditure is dissipated through marketing costs. Theory suggests that hospitals, physicians, and other health care providers could also capture some of the increased reimbursements, by virtue of market power. However, the aforementioned calculations leave relatively little for providers. The absence of stock price reaction from the largest publiclyowned hospital operator, HCA, on April 1, 2013, is also suggestive of limited benefits to providers. Altogether, increased financial generosity, increased insurer profits, and increased marketing account for nearly all of the increased government expenditures. Exploring the interaction between government reimbursement and insurer-provider bargaining is an important avenue for future work.

\footnotetext{
${ }^{20}$ The benchmark increase of $5.6 \%$ applied not only to 2014 benchmarks, but also to all future year benchmarks; for 2014, this resulted in a benchmark that was $1.2 \%$ higher than the expectation. In our calculations, we thereby assume that all future year benchmarks would also be $1.2 \%$ higher than expected. However, for some of these years, higher benchmarks may have already been anticipated; congressional action on Medicare SGR policies would produce a benchmark increase of commensurate magnitude and would supercede CMS's action. While CMS preempted such legislation through its unilateral action, following any Congressional legislation, past CMS action (or lack thereof) would not affect subsequent benchmarks. In our calculations, we do not account for this possibility. As such, our estimate of the unexpected revenue increase, from CMS's action, represents an upper-bound, meaning that our estimated pass-through rate to insurers represents a lower-bound.
} 


\section{Conclusion}

Our results strongly suggest that increased subsidies for private insurance in the Medicare market result in increased insurer advertising, but little additional monetary or medical benefit for consumers. ${ }^{21}$ Low pass-through cannot be attributed to selection and is, more likely, a result of market power. Altogether, the results indicate that incidence of the subsidy falls on the supply side of the market. This finding is further supported by insurer stock price movements throughout the passage and enactment of the Affordable Care Act.

While we find no direct evidence that benchmarks meaningfully benefit consumers, such benefits could exist. Given that MA penetration rates increase alongside reimbursements, a revealed preference argument would imply that MA is more valuable to consumers when the benchmark is higher. The impact on consumer surplus may also depend on the welfare consequences of advertising. Furthermore, higher benchmarks may improve treatment quality and health outcomes in ways that we are unable to measure. All of this notwithstanding, the measures of plan financial characteristics and quality that we use suggest that only about one-sixth of the policy-induced increase in plan reimbursement is captured by consumers.

While reimbursement increases have an ambiguous welfare impact on consumers, they unambiguously increase costs, through increased numbers of MA enrollees and through increased government spending per MA enrollee. A back-of-the-envelope estimate suggests that this additional spending amounted to approximately $\$ 6.4$ billion during the final year of our sample period. ${ }^{22}$ Therefore, policy-makers should carefully weigh the possible gains in consumer welfare against the costs to the federal government, and future work should attempt to quantify the full welfare benefit of increased reimbursements.

\footnotetext{
${ }^{21}$ The advertising is clearly market expanding if Medicare Advantage is the relevant market. However, the extent to which this is welfare enhancing depends on the view of advertising. We simply highlight that insurers in this market, as well as other insurance markets (Starc 2013), tend to compete on advertising, rather than plan generosity or innovative benefit packages.

${ }^{22}$ Approximately 5.0 million MA enrollees resided in floor counties in 2011. In non-floor counties, the benchmark is on average 6.1 percent higher than the lagged 5-year average FFS expenditure measure. If this same 6.1 percent ratio existed in floor counties, monthly (annual) benchmarks would be $\$ 63.09$ ( $\$ 757.08$ ) lower and spending for the 5.0 million MA enrollees would be $\$ 3.8$ billion lower. Additionally, our estimates for the effect of benchmarks on MA enrollment suggest the $\$ 63.09$ benchmark increase leads to about a 10.9 percentage point increase in MA enrollment. With 20.1 million Medicare recipients in floor counties, this represents about 2.2 million additional MA recipients. Recent research (Brown et al, 2014) indicates that switching into MA increases Medicare spending by more than $\$ 1,200$ per recipient because of favorable selection and this suggests about $\$ 2.6$ billion more in Medicare spending.
} 


\section{References}

Abaluck, J.T. and Gruber, J. "Choice Inconsistencies among the Elderly: Evidence from Plan Choice in the Medicare Part D Program." The American Economic Review, Vol. 101, (2011), pp. 1180-1210.

Afendulis, C., Chernew M., and Kessler, D. "The Effect of Medicare Advantage on Hospital Admissions and Mortality." NBER Working Paper No. 19101 National Bureau of Economic Research, Cambridge, 2013.

Al-Ississ, M. and Miller, N. "What Does Health Reform Mean for the Health Care Industry? Evidence from Massachusetts Special Senate Election." The American Economic Association, Vol. 5, (2013), pp. 1-29.

Balsa, A.I., Cao, Z., and McGuire, T.G. "Does Managed Health Care Reduce Health Care Disparities Between Minorities and Whites." The Journal of Health Economics, Vol. 26, (2007), pp. 101-121.

Brown, J., Duggan, M., Kuziemko, I., and Woolston, W. "How Does Risk Selection Respond to Risk Adjustment? Evidence from the Medicare Advantage Program." The American Economic Review, forthcoming.

Cabral, M., Geruso, M., and Mahoney, N. "Does Medicare Advantage Benefit Patients or Insurance Providers? Evidence from the Benefits Improvement and Protection Act." Working Paper, 2013.

Cabral, M. and Mahoney, N. "Externalities and Taxation of Supplemental Insurance: A Study of Medicare and Medigap." Working Paper, 2013.

Cawley, J., Chernew, M., McLaughlin, C. "HMO Participation in Medicare + Choice." Journal of Economics $\& 3$ Management Strategy, Vol. 14, (2005), pp. 543-574.

Chernew, M., Cutler, D., and Keenan, P. "Increasing Health Insurance Costs and the Decline in Insurance Coverage." Health Services Research, Health Research and Educational Trust. (2005), pp. 1021-1039.

Clemens, J. and Gottlieb, J.D. "Bargaining in the Shadow of a Giant: Medicare's Influence on Private Payment Systems." NBER Working Paper No. 19503, National Bureau of Economic Research, Cambridge, 2013. 
Center for Health Strategies Inc. (2006). "Medicare Advantage Rate Setting and Risk Adjustment."

Centers for Medicare \& Medicaid Services (2013). "National Health Expenditure Projections 2012-2022."

Congressional Budget Office (2012). "Effects of the Repeal of H.R. 6079."

Congressional Budget Office (2013). "Updated Budget Projections: Fiscal Years 2013 to 2023."

Dafny, L. "Are Health Insurance Markets Competitive?" The American Economic Review, Vol. 100, (2010), pp. 1399-1431.

Dafny, L. and Dranove, D. "Do Report Cards Tell Consumers Anything They Don't Already Know? The Case of Medicare HMOs." RAND Journal of Economics, Vol. 39, (2008), pp. 780-821.

Dafny, L., Duggan, M., and Ramanarayan, S. "Paying a Premium on Your Premium? Consolidation in the U.S. Health Insurance Industry." The American Economic Review, Vol. 102 (2012), pp. 1161-1185.

Dunn, A. "The Effect of Health Insurance Competition when Private Insurers Compete with a Public Option." (2011).

Einav, L., Finkelstein, A., and Schrimpf, P. "The Response of Drug Expenditures to Non-Linear Contract Design: Evidence from Medicare Part D." NBER Working Paper No. 19393, National Bureau of Economic Research, Cambridge, 2013.

Finkelstein, A., et al. "The Oregon Health Insurance Experiment: Evidence from the First Year. Quarterly Journal of Economics, Vol. 127, (2012), pp 1057-1106.

Frakt, A.B., Pizer, S.D., and Feldman, R. "Payment Reduction and Medicare Private Fee-forService Plans." Health Care Financing Review, Vol. 30, (2009), pp. 15-24.

Gaynor, M. and Town, R. "Competition in Health Care Markets." Working Paper No. 12/282, Centre for Market and Pulic Organisation, Bristol, 2012.

Gowrisankaran, G., Nevo, A., and Town, R. "Mergers When Prices Are Negotiated: Evidence from the Hospital Industry." NBER Working Paper No. 18875, National Bureau of Economic Research, Cambridge, 2013.

Hall, A. "The Value of Medicare Managed Care Plans and Their Prescription Drug Benefits." Federal Reserve Board of Governors, 2007.

Ho, K. and Lee, R. "Insurer Competition and Negotiated Hospital Prices." NBER Working 
Paper No. 19401, Natural Bureau of Economic Research, Cambridge, 2013.

Ketcham, J., Lucarilli, C., Miravete, E., and Roebuck, C. "Sinking, Swimming, or Learning to Swim in Medicare Part D." The American Economic Review, Vol. 102, (2012), pp. 2639-2673.

Kliff, S. "How insurers flipped a Medicare pay cut into a pay raise." The Washington Post, April 2010.

Kling, J., Liebman, J., and Katz, L. "Experimental Analysis of Neighborhood Effects." Econometrica, Vol. 75, (2007), pp. 83-119.

Kling, J., Mullainathan, S., Shafir, E., Vermeulen, L., and Wrobel, M. "Comparison Friction: Experimental Evidence from Medicare Drug Plans." The Quarterly Journal of Economics, Vol. 127, (2012), pp. 199-235.

Landon, B, Zaslavsky, A., Saunders, R., Pawlson, L., Newhouse, J., and Ayanian, J. "Analysis Of Medicare Advantage HMOs compared with traditional Medicare shows lower use of many services during 2003-09." Health Affairs, Vol. 31, (2012), pp. 2609-2617.

Lemieux, J., Sennett, C., Wang, R., Mulligan, T., Bumbaugh, J. "Hospital readmission rates in Medicare Advantage plans." American Journal of Managed Care, Vol. 18, (2012), pp 96-104.

Lustig, J. "Measuring Welfare Losses from Adverse Selection and Imperfect Competition in Privatized Medicare." Boston University, Department of Economics, Boston, 2010.

Mahoney, N., and Weyl, E.G. "Imperfect Competition in Selection Markets." Working Paper, 2013.

McGuire, T., Newhouse, J., and Sinaiko, A. "An Economic History of Medicare Part C." The Milbank Quarterly, Vol. 89, (2011), pp. 289-323.

Neal, D. "How Vouchers Could Change the Market for Education." The Journal of Economic Perspectives, Vol. 16, (2002), pp. 25-44.

Nosal, K. "Estimating Switching Costs for Medicare Advantage Plans." Unpublished manuscript, University of Mannheim, Mannheim, 2012.

OECD (2011). "Government at a Glance: Size of public procurement market."

Pizer, S.D. and Frakt, A.B. "Payment Policy and Competition in the Medicare+ Choice Program." Health Care Financing Review, Vol. 24, (2002), pp. 83-94.

Rouse, C. "Private School Vouchers and Student Achievement: An Evaluation of the Milwaukee Parental Choice Program." The Quarterly Journal of Economics, Vol. 113, (1998), pp. 553-602. 
Pope, G., Greenwald, L., Healy, D., Kauter, J., Olmsted, E., West, N. "Impact of Increased Financial Incentives to Medicare Advantage Plans." RTI International, 2006.

Song, Z., Landrum, M., and Chernew, M. "Competitive bidding in Medicare Advantage: Effect of benchmark changes on plan bids." Journal of Health Economics, Vol. 32, (2013), pp. 1301-1312.

Starc, A. "Insurer Pricing and Consumer Welfare: Evidence from Medigap." RAND Journal of Economics, forthcoming.

Town, R. and Liu, A. "The Welfare Impact of Medicare HMOs." RAND Journal of Economics, Vol. 34, (2003), pp. 719-736.

Weyl, G., and Fabinger, M. "Pass-Through as an Economic Tool: Principle of Incidence under Imperfect Competition." Journal of Political Economy, Vol. 121, (2013), pp. 528-583. 


\section{Tables and Figures}

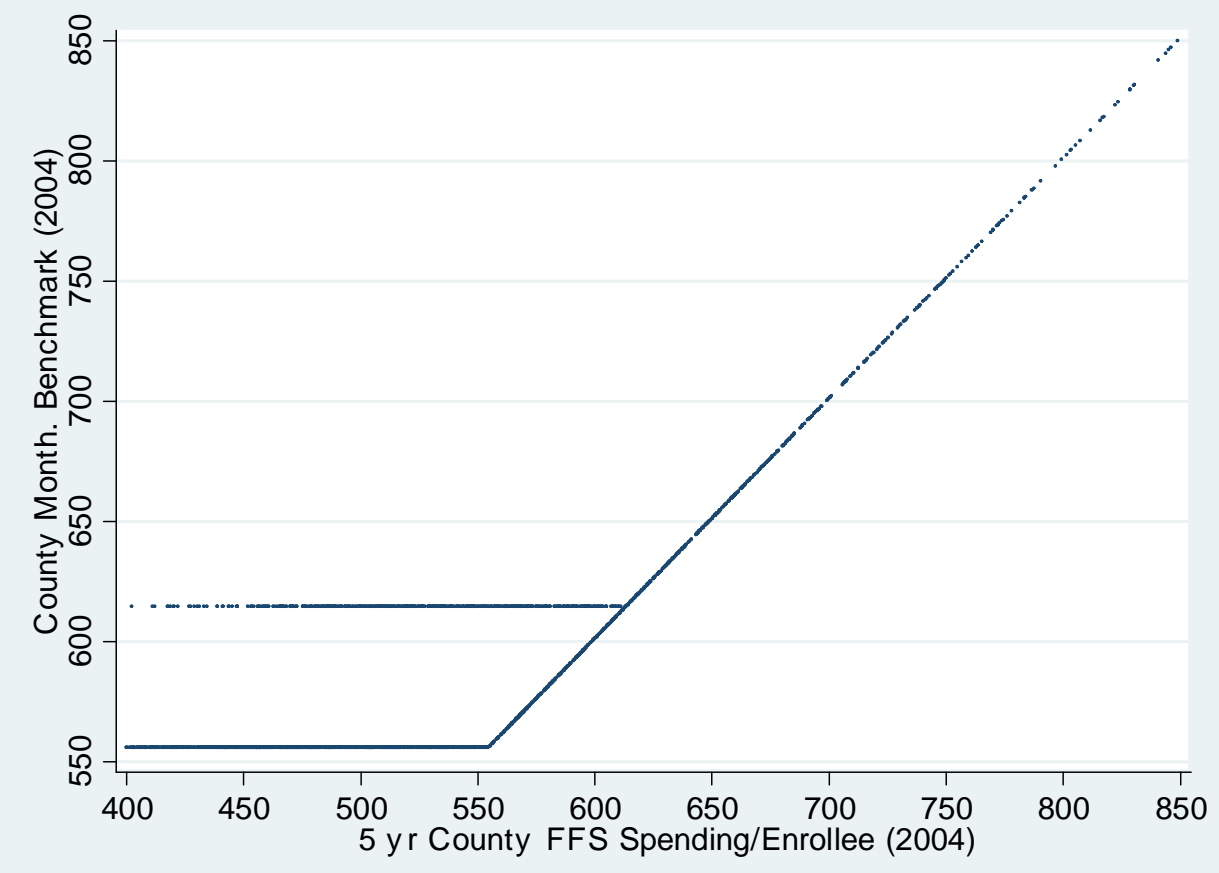

Figure 1: County Benchmarks and FFS Costs in 2004

\footnotetext{
${ }^{22}$ For fewer than $10 \%$ of counties, 2007 county benchmarks do not correspond to either a floor (two horizontal lines) or to a county's 5-yr FFS spending/enrollee (primary diagonal). This is due to ideosyncrasies in how county benchmarks were determined following 2004 (see CHS, 2006). For benchmarks as of 2007, see Appendix Figure 1.
} 


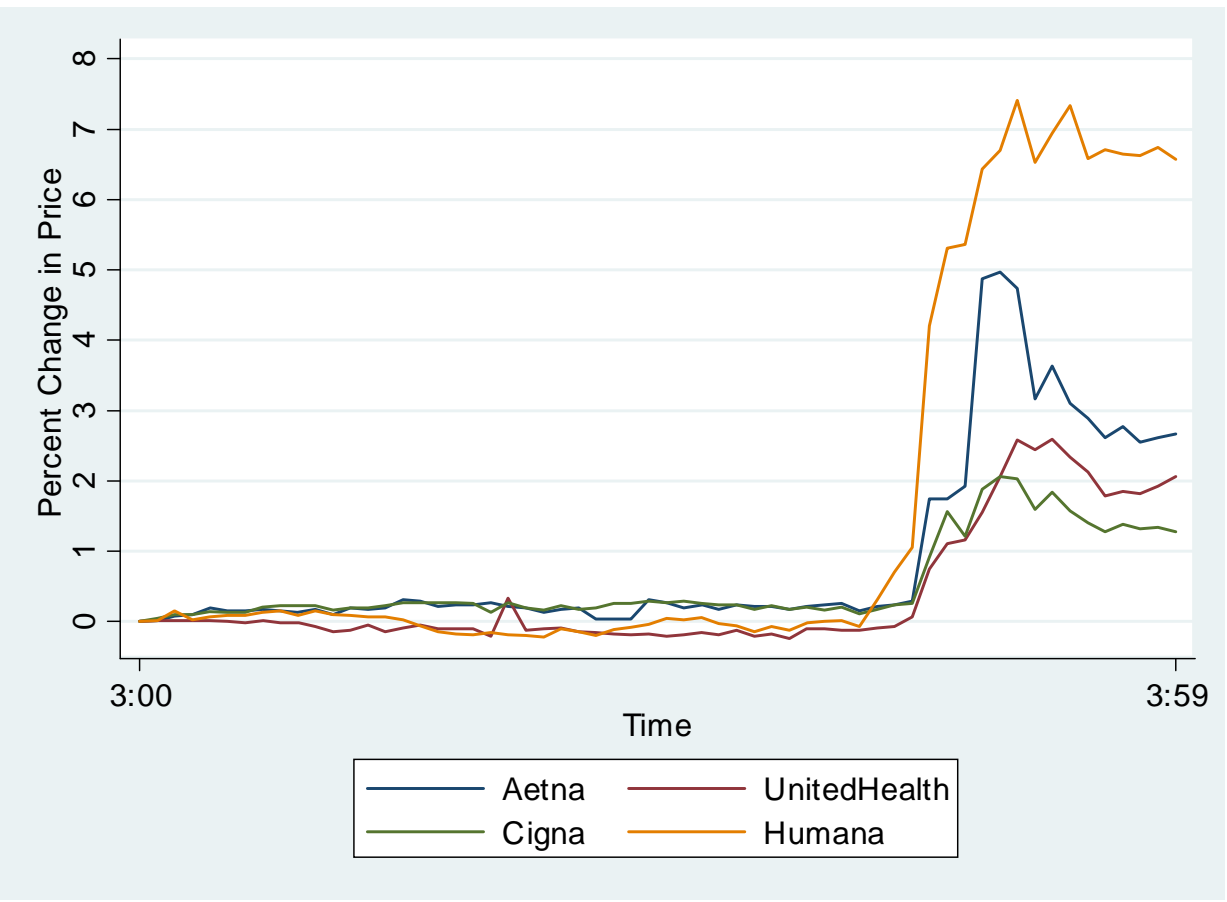

Figure 2: Stock Returns of Major MA Insurers, 3-4 pm on April 1, 2013
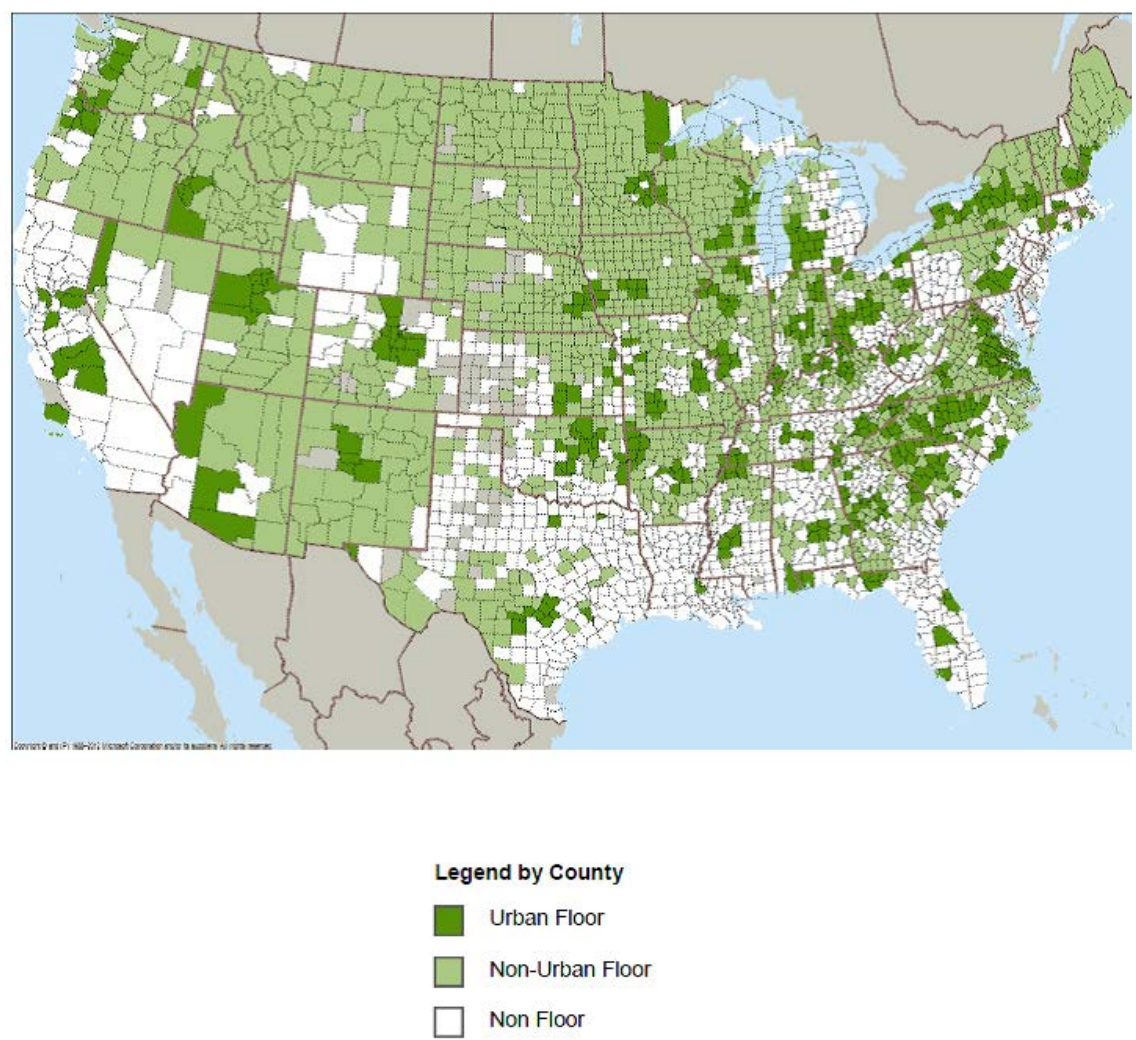

Figure 3: Nationwide Distribution of Floor Counties 


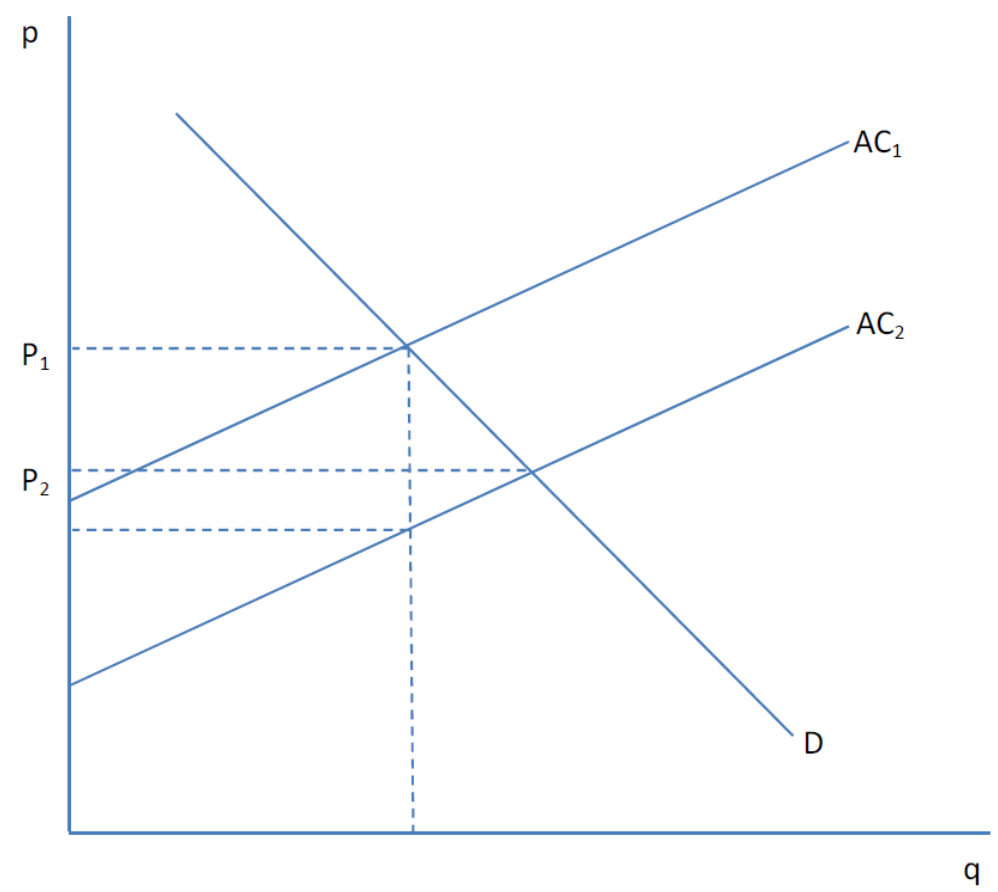

Figure 4: Pass-Through Under Advantageous Selection

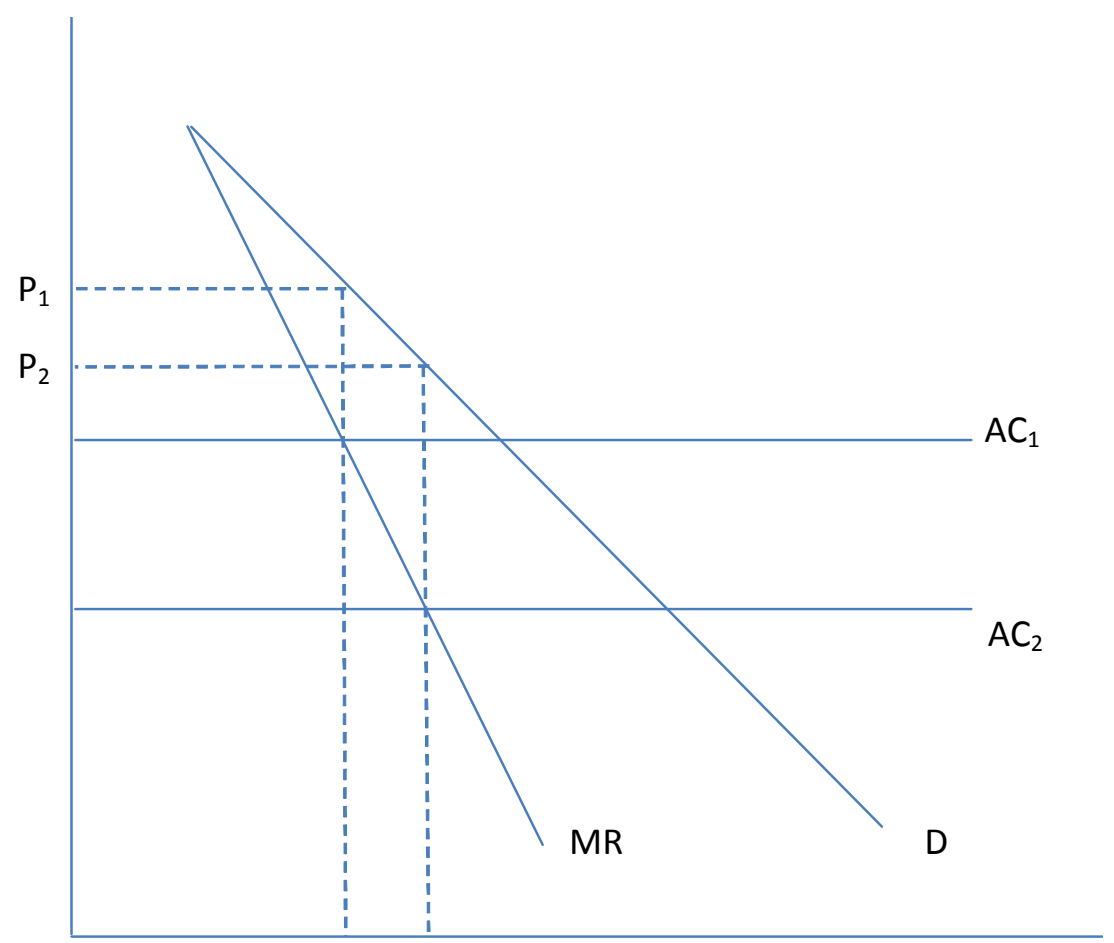

Figure 5: Pass-Through Under Constant Average Cost and Monopoly 


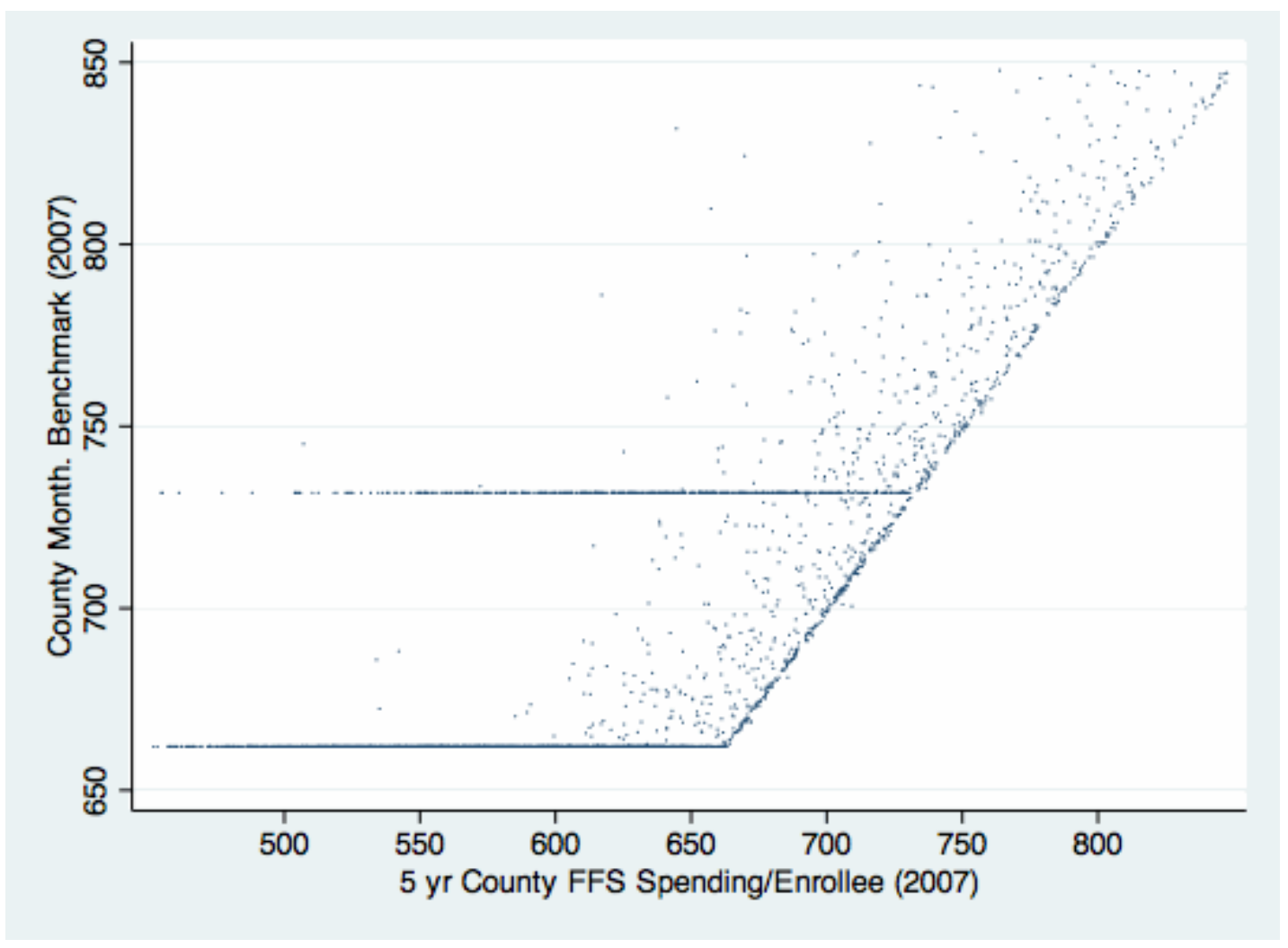

Appendix Figure I: FFS Costs and County Benchmarks

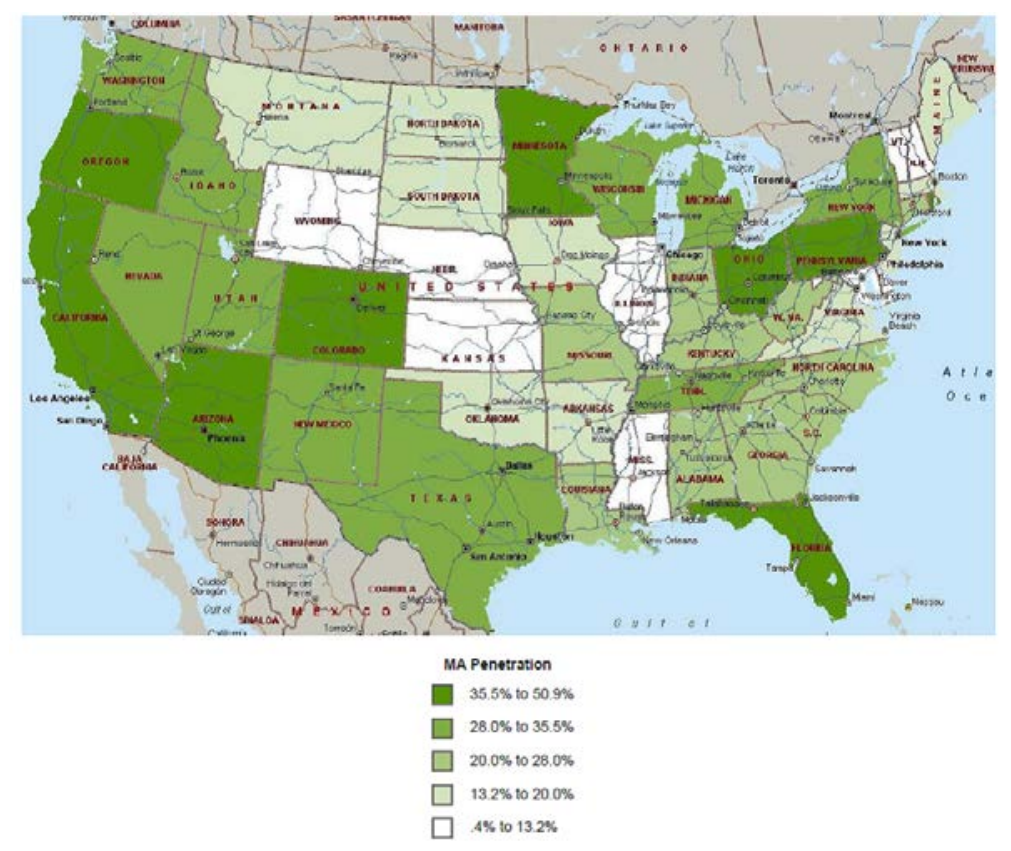

Appendix Figure II: 2014 Medicare Advantage Market Penetration, By State 


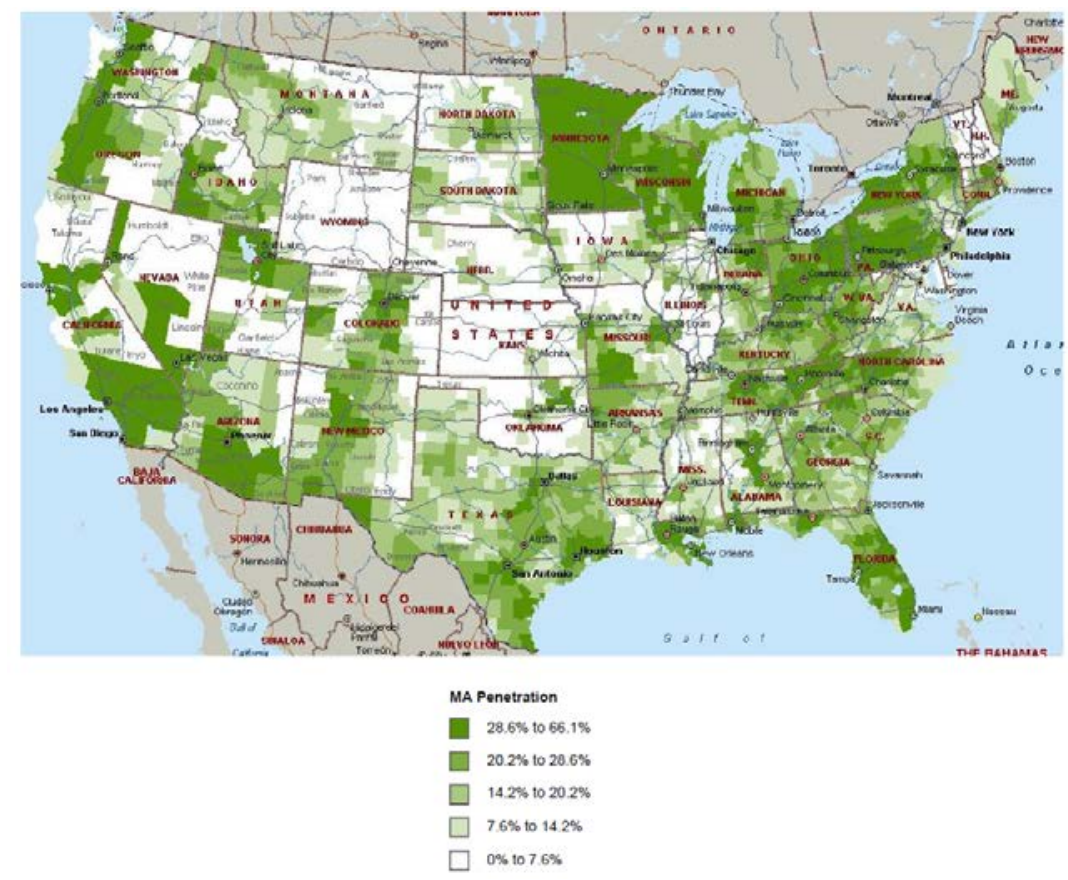

Appendix Figure III: 2014 Medicare Advantage Market Penetration, By County

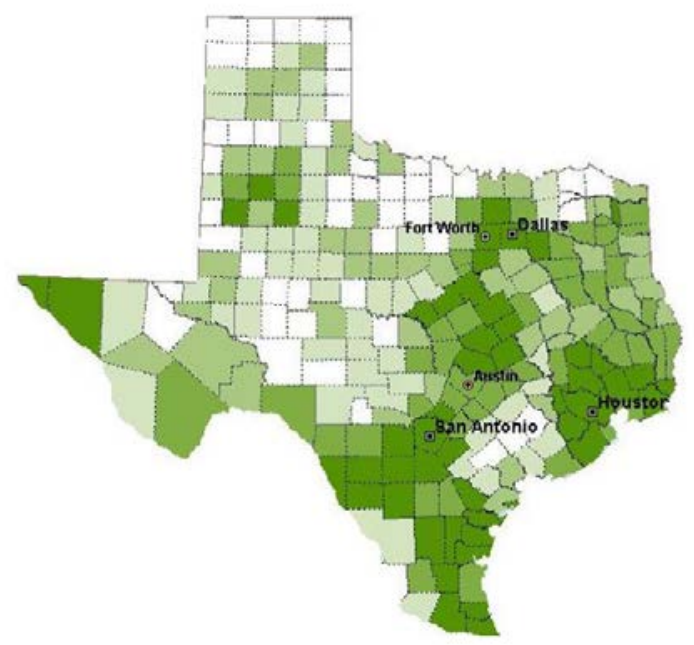

$$
\begin{aligned}
& \text { MA Penetration } \\
& \square \quad 25.0 \% \text { to } 46.1 \% \\
& \square \quad 20.5 \% \text { to } 25 \% \\
& \square \quad 16.6 \% \text { to } 20.5 \% \\
& \square \quad 13.4 \% \text { to } 16.6 \% \\
& \square \quad 0 \% \text { to } 13.4 \%
\end{aligned}
$$

Appendix Figure IV: 2014 Texas Medicare Advantage Market Penetration, By County 
Table 1: Summary Statistics: County \& Financial

\begin{tabular}{|c|c|c|c|c|}
\hline & All & Sub-Group 1 & Sub-Group 2 & Sub-Group 3 \\
\hline Per Capita 2007 FFS Rest: & None & Below 662 & $\begin{array}{c}\text { Above 662 } \\
\text { \& Below 732 }\end{array}$ & Above 732 \\
\hline Metro Pop (thousands) & $\begin{array}{c}472 \\
(1,209)\end{array}$ & $\begin{array}{c}239 \\
(661)\end{array}$ & $\begin{array}{c}616 \\
(1.103)\end{array}$ & $\begin{array}{c}1,109 \\
(2.180)\end{array}$ \\
\hline County Pop (thousands) & $\begin{array}{c}96 \\
(306)\end{array}$ & $\begin{array}{c}50 \\
(105)\end{array}$ & $\begin{array}{c}104 \\
(243)\end{array}$ & $\begin{array}{c}246 \\
(631)\end{array}$ \\
\hline Monthly Per Cap. FFS & $\begin{array}{l}680 \\
(104)\end{array}$ & $\begin{array}{l}615 \\
(60)\end{array}$ & $\begin{array}{l}732 \\
(29)\end{array}$ & $\begin{array}{l}839 \\
(72)\end{array}$ \\
\hline Medicare Enroll (thousands) & $\begin{array}{c}14.79 \\
(39.66)\end{array}$ & $\begin{array}{c}8.33 \\
(14.93)\end{array}$ & $\begin{array}{c}15.98 \\
(33.28)\end{array}$ & $\begin{array}{c}35.98 \\
(79.47)\end{array}$ \\
\hline MA Penetration Rate & $\begin{array}{c}0.12 \\
(0.10)\end{array}$ & $\begin{array}{c}0.12 \\
(0.10)\end{array}$ & $\begin{array}{c}0.11 \\
(0.09)\end{array}$ & $\begin{array}{c}0.14 \\
(0.13)\end{array}$ \\
\hline PFFS Penetration Rate & $\begin{array}{c}0.05 \\
(0.04)\end{array}$ & $\begin{array}{c}0.06 \\
(0.05)\end{array}$ & $\begin{array}{c}0.04 \\
(0.03)\end{array}$ & $\begin{array}{c}0.02 \\
(0.03)\end{array}$ \\
\hline HHI Index & $\begin{array}{c}5,117 \\
(2,212)\end{array}$ & $\begin{array}{c}5,168 \\
(2,244)\end{array}$ & $\begin{array}{c}5,070 \\
(2,168)\end{array}$ & $\begin{array}{c}5,002 \\
(2,155)\end{array}$ \\
\hline Floor Status (2007) & $\begin{array}{c}0.62 \\
(0.49)\end{array}$ & $\begin{array}{c}0.92 \\
(0.26)\end{array}$ & $\begin{array}{l}0.27 \\
(0.44)\end{array}$ & $\begin{array}{c}0.00 \\
(0.00)\end{array}$ \\
\hline MA Benchmark (Monthly) & $\begin{array}{l}764 \\
(75)\end{array}$ & $\begin{array}{l}726 \\
(32)\end{array}$ & $\begin{array}{l}771 \\
(32)\end{array}$ & $\begin{array}{l}888 \\
(84)\end{array}$ \\
\hline $\mathrm{N}$ & 3044 & 1850 & 667 & 527 \\
\hline Out of Pocket Costs (monthly) & $\begin{array}{l}380.1 \\
(38.8)\end{array}$ & $\begin{array}{l}391.7 \\
(32.7)\end{array}$ & $\begin{array}{l}369.6 \\
(33.0)\end{array}$ & $\begin{array}{l}352.6 \\
(47.0)\end{array}$ \\
\hline Rebate Payment (monthly) & $\begin{array}{c}58.3 \\
(22.5)\end{array}$ & $\begin{array}{c}53.6 \\
(15.7)\end{array}$ & $\begin{array}{c}59.3 \\
(17.8)\end{array}$ & $\begin{array}{l}73.3 \\
(37.0)\end{array}$ \\
\hline Premium (monthly) & $\begin{array}{c}32.3 \\
(19.8)\end{array}$ & $\begin{array}{c}31.2 \\
(18.4)\end{array}$ & $\begin{array}{c}33.4 \\
(19.2)\end{array}$ & $\begin{array}{l}34.6 \\
(24.5)\end{array}$ \\
\hline Premium+OOPC & $\begin{array}{l}412.5 \\
(43.7)\end{array}$ & $\begin{array}{l}423.2 \\
(35.7)\end{array}$ & $\begin{array}{l}403.0 \\
(38.2)\end{array}$ & $\begin{array}{l}387.2 \\
(59.6)\end{array}$ \\
\hline Premium+OOPC-Rebate Pmt & $\begin{array}{l}356.4 \\
(61.2)\end{array}$ & $\begin{array}{l}372.6 \\
(45.0)\end{array}$ & $\begin{array}{l}344.3 \\
(51.6)\end{array}$ & $\begin{array}{l}314.3 \\
(91.7)\end{array}$ \\
\hline $\mathrm{N}$ & 3028 & 1840 & 666 & 522 \\
\hline
\end{tabular}

Notes: The first panel presents summaries of demographic, MA penetration, and other characteristics for different sets of counties. The second panel presents summaries of the financial characteristics of MA plans, across different sets of counties. Measures are denoted per enrollee, per month. The unit of observation is aggregated to the county level, for the 2007-2011 period, and is weighed based on plan enrollment. The original data is obtained from publicly available CMS files, including simulated out of pocket cost information, premium metrics, as well as other data. 
Table 2: Most Active Firms in Markets of Interest

\begin{tabular}{rcccc}
\hline \hline & All & Sub-Group 1 & Sub-Group 2 & Sub-Group 3 \\
Per Capita 2007 FFS Rest: & None & Below 662 & $\begin{array}{c}\text { Above 662 } \\
\text { EG }\end{array}$ & Below 732 \\
& & & & \\
\hline Humana Inc. & 12,998 & 8,094 & 2,840 & 2,064 \\
UnitedHealth Group, Inc. & 7,146 & 4,444 & 1,407 & 1,295 \\
Universal American Corp. & 5,844 & 3,511 & 1,356 & 977 \\
Coventry Health Care Inc. & 5,463 & 3,427 & 1,121 & 915 \\
WellPoint, Inc. & 5,100 & 3,303 & 1,082 & 715 \\
Aetna Inc. & 4,042 & 1,826 & 1,077 & 1,139 \\
XLHealth Corporation & 2,099 & 974 & 677 & 448 \\
WellCare Health Plans, Inc. & 1,910 & 980 & 410 & 520 \\
Blue Cross Blue Shield of Michigan & 1,466 & 620 & 425 & 421 \\
& $\mathbf{1 5 , 0 2 0}$ & $\mathbf{9 , 4 3 0}$ & $\mathbf{3 , 1 6 0}$ & $\mathbf{2 , 4 3 0}$ \\
\hline \hline
\end{tabular}

Notes: Table presents number of county-year units through which any given firm offers contracts, where enrollment exceeds 10. This analysis extends for the period 2007-2011. The original data is obtained from publicly available CMS files, including contract-county level enrollment data and contract characteristics data. 
Table 3: First Stage Regression Results

\begin{tabular}{|c|c|c|c|c|c|c|c|c|}
\hline \multirow[b]{2}{*}{ VARIABLES } & 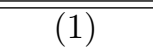 & (2) & 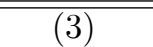 & 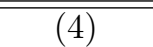 & 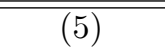 & (6) & (7) & 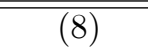 \\
\hline & \multicolumn{8}{|c|}{ County Benchmark } \\
\hline Urban & $\begin{array}{c}71.56^{* * *} \\
(0.79)\end{array}$ & $\begin{array}{c}71.46^{* * *} \\
(237)\end{array}$ & $\begin{array}{c}20.01^{* * *} \\
(3.44)\end{array}$ & $\begin{array}{l}22.72^{*} \\
(1155)\end{array}$ & $\begin{array}{c}3.31 \\
(5.99)\end{array}$ & $\begin{array}{l}-22.15^{*} \\
(12.93)\end{array}$ & $\begin{array}{c}0.50 \\
(4.32)\end{array}$ & $\begin{array}{l}-10.55 \\
(9-20)\end{array}$ \\
\hline Urban*GAP & & & & & & & $46.44^{* * *}$ & $55.24^{* * *}$ \\
\hline & & & & & & & $(5.68)$ & $(13.48)$ \\
\hline GAP & & & & & & & $10.99^{*}$ & 2.81 \\
\hline & & & & & & & $(5.79)$ & $(13.88)$ \\
\hline \multirow{2}{*}{ County Pop (100k) } & 0.078 & -1.674 & -0.532 & -1.660 & $-1.891^{* * *}$ & -8.322 & $-1.310^{* * *}$ & -6.879 \\
\hline & $(0.517)$ & $(1.496)$ & $(0.813)$ & $(5.104)$ & $(0.612)$ & $(7.832)$ & $(0.463)$ & $(4.411)$ \\
\hline \multirow[t]{2}{*}{ County Pop (100k) Sq } & 0.017 & 0.515 & 0.019 & 0.181 & $0.025^{* * *}$ & 0.616 & $0.020^{* * *}$ & 0.799 \\
\hline & $(0.039)$ & $(0.478)$ & $(0.026)$ & $(0.948)$ & $(0.008)$ & $(1.447)$ & $(0.007)$ & $(0.817)$ \\
\hline \multirow[t]{2}{*}{ Metro Pop } & 0.035 & 0.608 & $0.664^{* *}$ & 1.594 & $0.490^{*}$ & $22.989^{*}$ & $0.459 * *$ & 8.753 \\
\hline & $(0.099)$ & $(3.021)$ & $(0.285)$ & $(13.582)$ & $(0.272)$ & $(13.297)$ & $(0.209)$ & $(9.941)$ \\
\hline \multirow[t]{2}{*}{ Metro Pop Sq } & 0.000 & -0.097 & $-0.008^{*}$ & -0.282 & $-0.005^{* *}$ & -2.234 & $-0.005^{* * *}$ & -0.797 \\
\hline & $(0.002)$ & $(0.371)$ & $(0.005)$ & $(1.610)$ & $(0.002)$ & $(1.743)$ & $(0.002)$ & $(1.211)$ \\
\hline \multirow[t]{2}{*}{2007 FFS 5-Yr } & $0.039 * * *$ & $0.038 * * *$ & $0.665^{* * *}$ & $0.549 * * *$ & $1.142^{* * *}$ & $1.063^{* * *}$ & $1.157^{* * *}$ & $1.154^{* * *}$ \\
\hline & $(0.005)$ & $(0.013)$ & $(0.056)$ & $(0.136)$ & $(0.038)$ & $(0.061)$ & $(0.032)$ & $(0.049)$ \\
\hline \multirow[t]{2}{*}{$\begin{array}{r}\text { Pop. } \\
\text { FFS }(\mathbf{2 0 0 7})\end{array}$} & $\begin{array}{l}\text { None } \\
<\boldsymbol{6 6 2}\end{array}$ & $\begin{array}{c}100-600 \mathrm{k} \\
\boldsymbol{B}<\boldsymbol{6 6} 2\end{array}$ & $\begin{array}{l}\text { None } \\
>\mathbf{6 6} 2\end{array}$ & $\begin{array}{c}100-600 \mathrm{k} \\
>\boldsymbol{6} \boldsymbol{6} 2\end{array}$ & $\begin{array}{l}\text { None } \\
>732\end{array}$ & $\begin{array}{c}100-600 \mathrm{k} \\
>\mathbf{7 3 2}\end{array}$ & $\begin{array}{l}\text { None } \\
>\mathbf{6 6 2}\end{array}$ & $\begin{array}{c}100-600 \mathrm{k} \\
>\mathbf{6 6} \boldsymbol{2}\end{array}$ \\
\hline & & & $63<732$ & $6<<732$ & & & & \\
\hline Observations & 9,230 & 1,740 & 3,330 & 650 & 2,640 & 490 & 5,970 & 1,140 \\
\hline R-squared & 0.945 & 0.970 & 0.630 & 0.673 & 0.892 & 0.799 & 0.904 & 0.873 \\
\hline
\end{tabular}

of interest. $\mathrm{T}=(732.04$ - FFS Avg) /69.7 if FFS Avg is $>662.3$ and $<732.04$ and otherwise 0 . The unit of observation is at the county-year level, for the 2007-2011 period. The original data is obtained from publicly available CMS files, including enrollment and other data. Note that populations are stated in terms of $100 \mathrm{k}$. 
Table 4: Reimbursement Impact: Market Structure and Plan Penetration

\begin{tabular}{|c|c|c|c|c|c|}
\hline VARIABLES & $\begin{array}{c}(1) \\
\text { Insurers }\end{array}$ & $\begin{array}{c}(2) \\
\text { HHI }\end{array}$ & $\begin{array}{c}(3) \\
\mathrm{HMO}+\mathrm{PPO} \text { Sh. }\end{array}$ & $\begin{array}{c}(4) \\
\text { PFFS Sh. }\end{array}$ & $\begin{array}{c}(5) \\
\text { MA Sh. }\end{array}$ \\
\hline Urban & $\begin{array}{c}1.917^{* * *} \\
(0.532)\end{array}$ & $\begin{array}{c}-1,047^{* *} \\
(466)\end{array}$ & $\begin{array}{c}0.070^{* * *} \\
(0.024)\end{array}$ & $\begin{array}{c}0.053^{* * *} \\
(0.015)\end{array}$ & $\begin{array}{c}0.123^{* * *} \\
(0.027)\end{array}$ \\
\hline 2007 FFS 5-yr (100s) & $\begin{array}{c}-0.618^{* * *} \\
(0.236)\end{array}$ & $\begin{array}{c}596^{* * *} \\
(182)\end{array}$ & $\begin{array}{c}-0.034^{* *} \\
(0.017)\end{array}$ & $\begin{array}{c}-0.033^{* * *} \\
(0.008)\end{array}$ & $\begin{array}{c}-0.067 * * * \\
(0.017)\end{array}$ \\
\hline Metro Pop (100k) & $\begin{array}{l}-0.434 \\
(0.699)\end{array}$ & $\begin{array}{c}331 \\
(587)\end{array}$ & $\begin{array}{l}-0.009 \\
(0.025)\end{array}$ & $\begin{array}{l}-0.021 \\
(0.018)\end{array}$ & $\begin{array}{l}-0.030 \\
(0.026)\end{array}$ \\
\hline Metro Pop (100k) Sq & $\begin{array}{c}0.028 \\
(0.106)\end{array}$ & $\begin{array}{l}-27 \\
(80)\end{array}$ & $\begin{array}{c}0.001 \\
(0.004)\end{array}$ & $\begin{array}{c}0.002 \\
(0.002)\end{array}$ & $\begin{array}{c}0.002 \\
(0.004)\end{array}$ \\
\hline Cnty Pop (100k) & $\begin{array}{c}3.682^{* * *} \\
(0.338)\end{array}$ & $\begin{array}{c}-1,413^{* * *} \\
(251)\end{array}$ & $\begin{array}{c}0.044^{* * *} * \\
(0.011)\end{array}$ & $\begin{array}{l}-0.000 \\
(0.006)\end{array}$ & $\begin{array}{c}0.043^{* * *} \\
(0.012)\end{array}$ \\
\hline Cnty Pop (100k) Sq & $\begin{array}{c}-0.543^{* * *} \\
(0.107)\end{array}$ & $\begin{array}{c}260 * * * \\
(69)\end{array}$ & $\begin{array}{c}-0.007^{* *} \\
(0.003)\end{array}$ & $\begin{array}{l}-0.001 \\
(0.002)\end{array}$ & $\begin{array}{c}-0.008^{* *} \\
(0.003)\end{array}$ \\
\hline $\begin{array}{r}\text { Additional Controls } \\
\text { Counties }\end{array}$ & \multicolumn{5}{|c|}{ Year } \\
\hline Mean & $\begin{array}{c}6.17 \\
(2.940)\end{array}$ & $\begin{array}{c}3,937 \\
(1,849)\end{array}$ & $\begin{array}{c}0.092 \\
(0.106)\end{array}$ & $\begin{array}{c}0.074 \\
(0.061)\end{array}$ & $\begin{array}{c}0.167 \\
(0.109)\end{array}$ \\
\hline $\mathrm{N}$ & 1,740 & 1,728 & 1,740 & 1,740 & 1,740 \\
\hline R-squared & 0.557 & 0.187 & 0.285 & 0.271 & 0.304 \\
\hline
\end{tabular}

Notes: Table presents linear regression models, where outcome variables are measures of MA market structure and the financial characteristics of MA plans. The unit of observation is aggregated at the county-year, for the 2007-2011 period. The original data is obtained from publicly available CMS files, including enrollment, landscape, OOPC, and other data. We exclude counties whose adjusted FFS level-as of 2007-was above that of the lowest possible floor. Finally, we restrict to those counties within the specified population band. We include controls for year and 2007 per capita Medicare FFS spending. We also include quadratic population controls, for counties as well as metros. Populations are stated in terms of $100 \mathrm{k}$. Standard errors are clustered at the metro-level. 
Table 5: Reimbursement Impact: Plan Characteristics

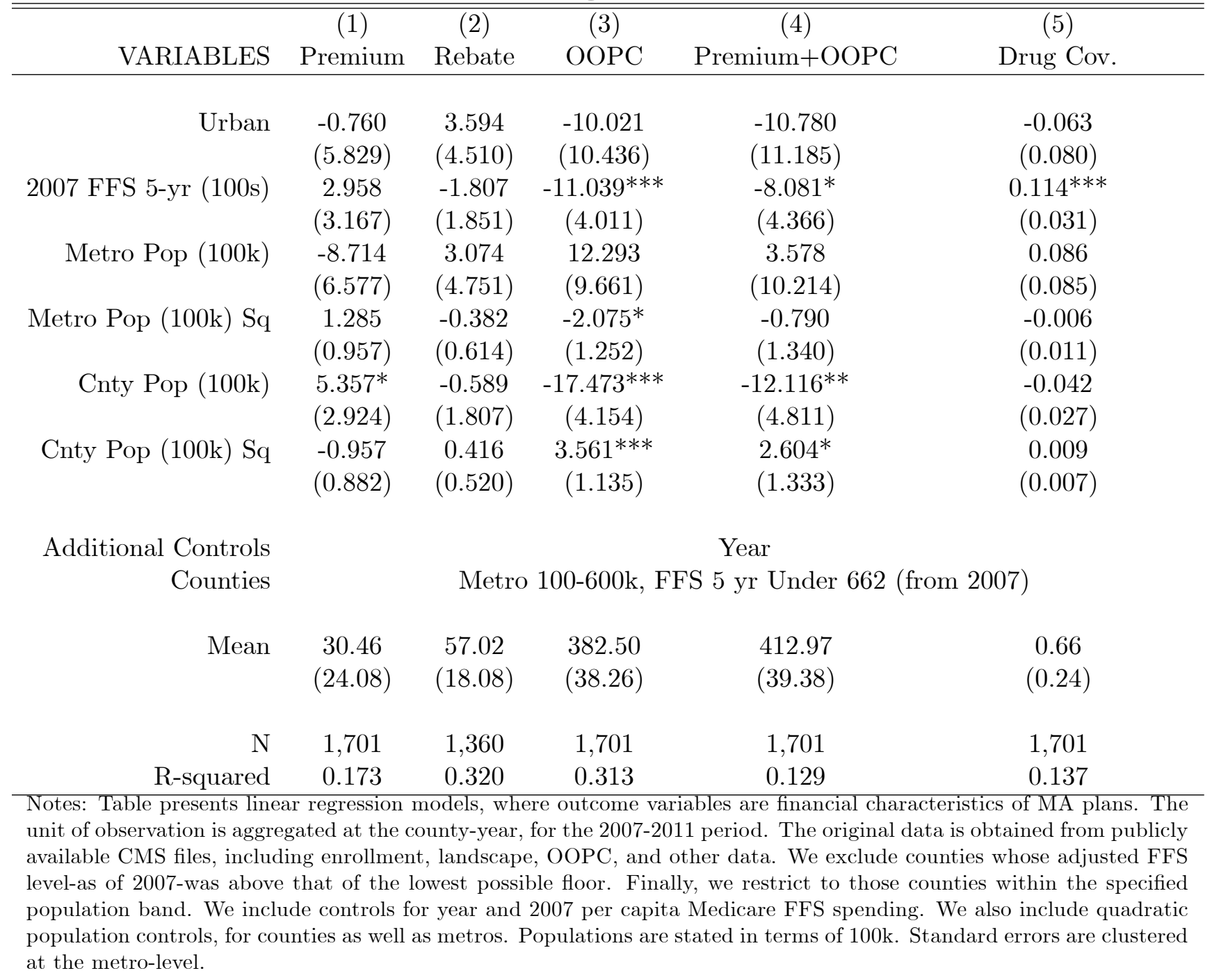


Table 6: Summary Statistics: CAHPS Data

\begin{tabular}{|c|c|c|c|c|}
\hline & \multirow[t]{2}{*}{ All } & \multirow[t]{2}{*}{ "100-600k } & \multicolumn{2}{|c|}{$\overline{\text { 100-600k, FFS Blw Floors }}$} \\
\hline & & & Urban & Non-Urban \\
\hline \multirow[t]{2}{*}{ Overall Healthcare Received } & 8.45 & 8.49 & 8.52 & 8.48 \\
\hline & $(0.71)$ & $(0.49)$ & $(0.38)$ & $(0.60)$ \\
\hline \multirow[t]{2}{*}{ Primary Care Physician } & 9.00 & 9.02 & 9.03 & 9.03 \\
\hline & $(0.58)$ & $(0.37)$ & $(0.31)$ & $(0.45)$ \\
\hline \multirow{2}{*}{ Specialist Physicians Seen } & 8.85 & 8.90 & 8.92 & 8.89 \\
\hline & $(0.79)$ & $(0.50)$ & $(0.32)$ & $(0.69)$ \\
\hline \multirow[t]{2}{*}{ Overall Health Plan } & 8.30 & 8.34 & 8.42 & 8.30 \\
\hline & $(0.80)$ & $(0.58)$ & $(0.43)$ & $(0.70)$ \\
\hline \multirow[t]{2}{*}{ Prescription Drug Benefits } & 8.32 & 8.33 & 8.40 & 8.27 \\
\hline & $(0.86)$ & $(0.57)$ & $(0.38)$ & $(0.69)$ \\
\hline \multirow[t]{2}{*}{ Specialists Seen } & 1.66 & 1.70 & 1.67 & 1.64 \\
\hline & $(0.44)$ & $(0.31)$ & $(0.24)$ & $(0.35)$ \\
\hline \multirow[t]{2}{*}{ Visits to Personal MD } & 2.01 & 1.97 & 1.94 & 1.89 \\
\hline & $(0.63)$ & $(0.51)$ & $(0.39)$ & $(0.59)$ \\
\hline \multirow{2}{*}{ Visits for Routine Care } & 2.29 & 2.33 & 2.28 & 2.29 \\
\hline & $(0.66)$ & $(0.48)$ & $(0.35)$ & $(0.62)$ \\
\hline \multirow[t]{2}{*}{ Self-Reported Overall Health Status } & 2.96 & 2.95 & 2.93 & 2.94 \\
\hline & $(0.41)$ & $(0.31)$ & $(0.26)$ & $(0.37)$ \\
\hline \multirow[t]{2}{*}{ Self-Reported Mental Health Status } & 2.27 & 2.27 & 2.27 & 2.28 \\
\hline & $(0.42)$ & $(0.31)$ & $(0.26)$ & $(0.37)$ \\
\hline No. Obs & 2,923 & 560 & 167 & 195 \\
\hline
\end{tabular}


Table 7: CAHPS Ratings

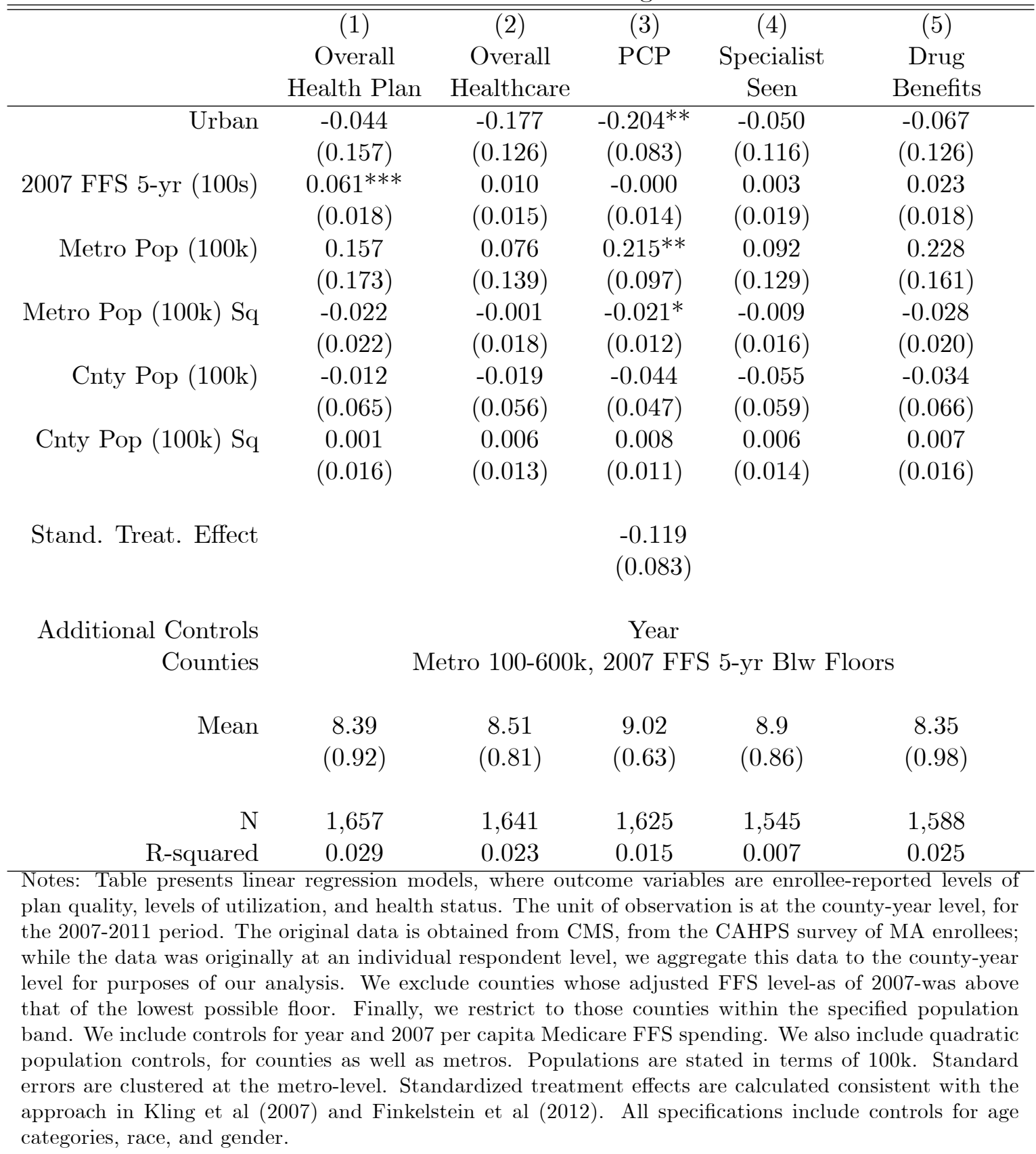


Table 8: CAHPS Utilization and Health

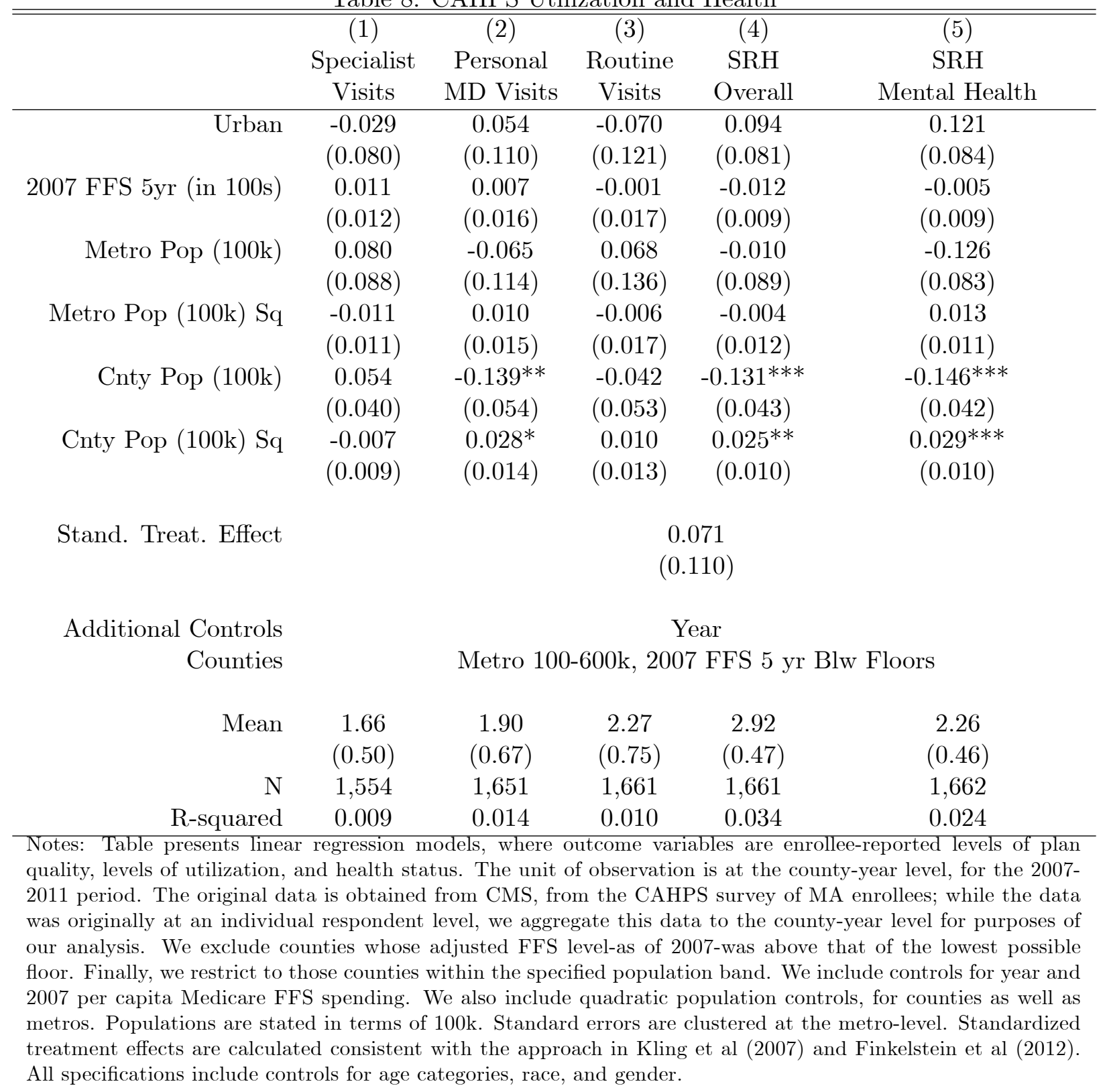


Table 9: Discharge Analyses

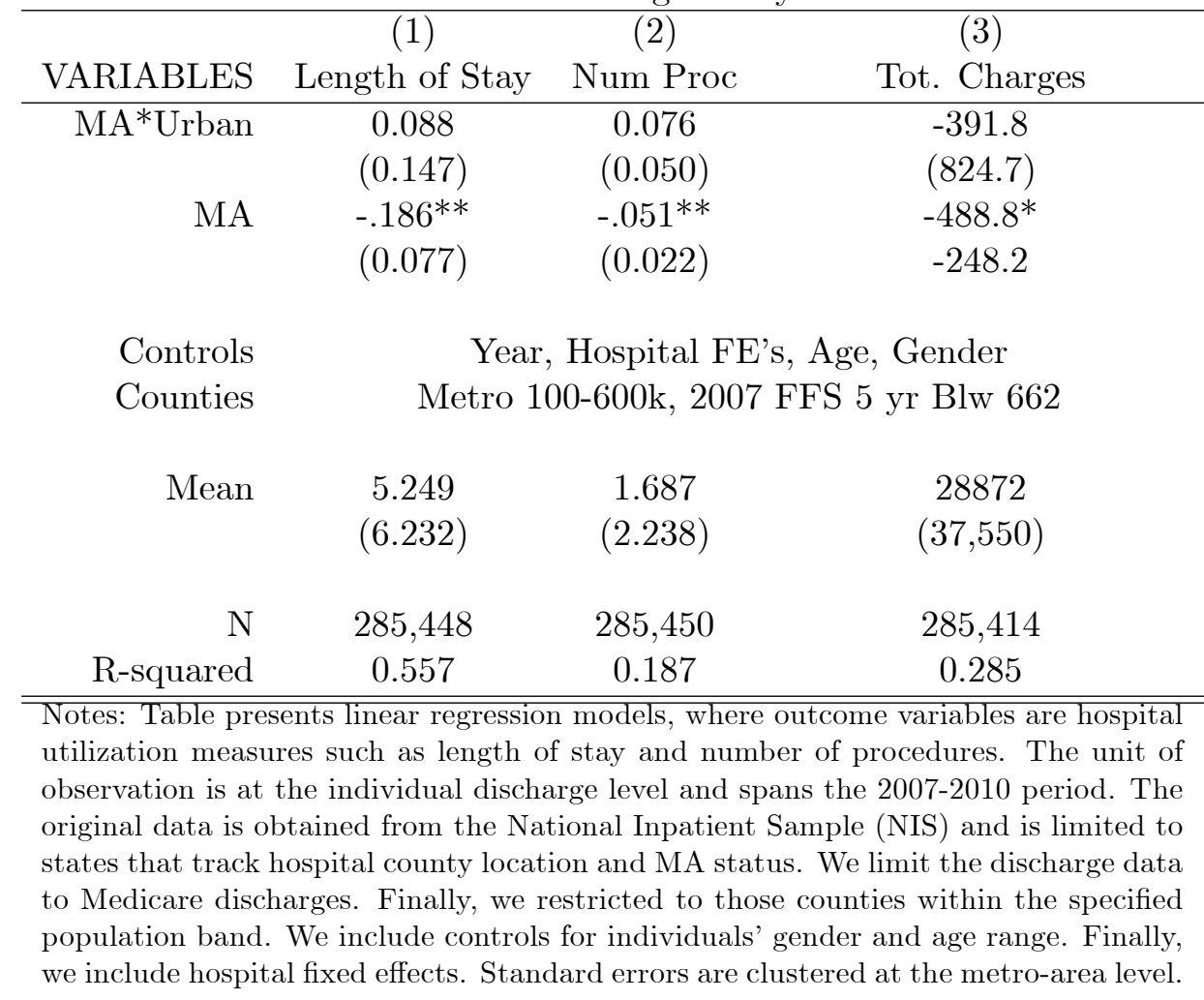

Table 10: MA Enrollment Composition Analyses: From CAHPS Data

\begin{tabular}{lcc}
\hline \hline & $\begin{array}{c}\text { 100-600k Metro \& } \\
\text { Urban }\end{array}$ & $\begin{array}{c}\text { Non-Urban } \\
\text { Agelow Floors }\end{array}$ \\
\hline Age & & \\
$65-74$ & $31.9 \%$ & $29.5 \%$ \\
$75-80$ & $24.7 \%$ & $24.6 \%$ \\
$81-84$ & $17.2 \%$ & $17.9 \%$ \\
$85+$ & $12.0 \%$ & $13.1 \%$ \\
Unknown & $7.5 \%$ & $8.8 \%$ \\
& & \\
White & $90.2 \%$ & $91.8 \%$ \\
Female & $54.1 \%$ & $53.7 \%$ \\
& & \\
MD Visits & 1.77 & 1.76 \\
Specialist Visits & 1.67 & 1.66 \\
Routine Care Visits & 2.17 & 2.18 \\
General Health Self-Assess & 2.77 & 2.78 \\
Mental Health Self-Assess & 2.11 & 2.12 \\
\hline Note: The original data is obtained from the CAHPS survey, at an \\
individual respondent level, for the years 2007-2011. These summary \\
statistics are based on individual respondent-level data.
\end{tabular}


Table 11: MA Composition \& Bid Analysis

\begin{tabular}{|c|c|c|c|}
\hline & $\begin{array}{c}(1) \\
\text { Mean Enrollee } \\
\text { Risk Score } \\
\end{array}$ & $\begin{array}{c}(2) \\
\text { Bid, as } \\
\text { Fract of Bnchmk }\end{array}$ & $\begin{array}{c}\text { (3) } \\
\text { Bid } \\
\text { Tot Amount }\end{array}$ \\
\hline Urban & $\begin{array}{c}0.021 \\
(0.025)\end{array}$ & $\begin{array}{c}\mathbf{0 . 0 0 4} \\
(0.008)\end{array}$ & \\
\hline Instr. County Benchmark & & & $\begin{array}{c}\mathbf{0 . 9 3 3} * * * \\
(0.082)\end{array}$ \\
\hline 2007 FFS 5yr (in 100s) & $\begin{array}{c}0.065^{* * *} \\
-0.009\end{array}$ & $\begin{array}{c}0.004 \\
(0.003)\end{array}$ & $\begin{array}{l}2.634 \\
(2.411)\end{array}$ \\
\hline Metro Pop (100k) & $\begin{array}{c}0.005 \\
(0.029)\end{array}$ & $\begin{array}{l}-0.006 \\
(0.009)\end{array}$ & $\begin{array}{l}-4.106 \\
(6.215)\end{array}$ \\
\hline Metro Pop (100k) Sq & $\begin{array}{c}-0.002 \\
(0.004)\end{array}$ & $\begin{array}{c}0.001 \\
(0.001)\end{array}$ & $\begin{array}{c}0.507 \\
(0.805)\end{array}$ \\
\hline Cnty Pop (100k) & $\begin{array}{c}0.013 \\
(0.009)\end{array}$ & $\begin{array}{c}0.001 \\
(0.003)\end{array}$ & $\begin{array}{c}0.699 \\
(2.398)\end{array}$ \\
\hline Cnty Pop (100k) Sq & $\begin{array}{l}-0.003 \\
(0.002)\end{array}$ & $\begin{array}{l}-0.001 \\
(0.001)\end{array}$ & $\begin{array}{c}-0.524 \\
(0.69)\end{array}$ \\
\hline $\begin{array}{r}\text { Additional Controls } \\
\text { Counties }\end{array}$ & \multicolumn{3}{|c|}{$\begin{array}{c}\text { Year } \\
\text { Metro 100-600k, } \\
\& 2007 \text { FFS } 5 \text { yr Blw } 662\end{array}$} \\
\hline Mean & $\begin{array}{c}0.885 \\
(0.081)\end{array}$ & $\begin{array}{c}0.897 \\
(0.034)\end{array}$ & $\begin{array}{l}665.76 \\
(52.55)\end{array}$ \\
\hline $\mathrm{N}$ & 1,724 & 1,360 & 1,360 \\
\hline R-squared & 0.197 & 0.339 & 0.858 \\
\hline
\end{tabular}

\footnotetext{
Notes: Table presents linear regression model, where outcome variable include average risk scores of MA enrollees and plan bids. The unit of observation is aggregated to the county-year level. The underlying data is from CMS, with the risk score data covering the 2007-2011 period and the bid data covering the 2007-2010 period.
}

Table 12: MA Composition-New York State Analysis

\begin{tabular}{lccccc}
\hline & $(1)$ & $(2)$ & $(3)$ & $(4)$ & $(5)$ \\
& Female & Age & White & Black & Hispanic \\
\hline Floor Prem (in hundreds/month) & $0.10 \%$ & 0.23 & $2.3 \%^{* *}$ & $-0.82 \%$ & $-0.17 \%^{* *}$ \\
& $(0.52)$ & $(0.24)$ & $(1.01)$ & $(0.54)$ & $(0.08)$ \\
Controls & $56.2 \%$ & 74.6 & $93.7 \%$ & $3.7 \%$ & $1.0 \%$ \\
Mean & $(9.2)$ & $(2.2)$ & $(9.8)$ & $(6.8)$ & $(2.9)$ \\
& 366 & 366 & 366 & 366 & 366 \\
$\mathrm{~N}$ & 0.89 & 0.87 & 0.99 & 0.99 & 0.99 \\
R-Squared & \multicolumn{5}{c}{ Year, County } \\
\hline \hline
\end{tabular}


Table 13: Advertising Spending

\begin{tabular}{rcccc}
\hline \hline & $(1)$ & $(2)$ & $(3)$ & $(4)$ \\
\hline & & & & \\
Benchmark & 0.169 & & $5.373^{* * *}$ & $4.510^{* * *}$ \\
& $(1.101)$ & & $(1.555)$ & $(1.534)$ \\
Current FFS Spending & & $-2.541^{* * *}$ & $-5.378^{* * *}$ & $-5.256^{* * *}$ \\
& & $(0.808)$ & $(1.148)$ & $(1.133)$ \\
Controls & pop & pop & pop & pop \\
& & & & ad price \\
Mean & 5.898 & 5.898 & 5.898 & 5.898 \\
& & & & 840 \\
Observations & 840 & 840 & 840 & 0.108 \\
R-squared & 0.041 & 0.053 & 0.066 & \\
\hline \hline
\end{tabular}

Notes: Table presents results of an OLS regression with TV spot advertising expenditures, per Medicare beneficiary per year, as the dependent variable, and the benchmark (per MA enrollee per month) as the explanatory variable of interest. The unit of observation is the DMA-year. Benchmarks are expressed in hundreds of dollars. Population controls are metro population and metro population squared, and the advertising price index is SQAD points. 